\title{
Identification of dividing, determined sensory neuron precursors in the
} \section{mammalian neural crest}

\author{
Amy L. Greenwood ${ }^{1}$, Eric E. Turner ${ }^{2}$ and David J. Anderson ${ }^{1, *}$ \\ ${ }^{1}$ Division of Biology 216-76, Howard Hughes Medical Institute, California Institute of Technology, Pasadena, CA 91125, USA \\ 2Department of Psychiatry, 0603, University of California, San Diego, San Diego VA Medical Center, La Jolla, CA 92093, USA \\ *Author for correspondence (e-mail: mancusog@caltech.edu)
}

Accepted 28 May; published on WWW 19 July 1999

\section{SUMMARY}

Sensory and autonomic neurons of the vertebrate peripheral nervous system are derived from the neural crest. Here we use the expression of lineage-specific transcription factors as a means to identify neuronal subtypes that develop in rat neural crest cultures grown in a defined medium. Sensory neurons, identified by expression of the POU-domain transcription factor Brn3.0, develop from dividing precursors that differentiate within 2 days following emigration from the neural tube. Most of these precursors generate sensory neurons even when challenged with BMP2, a factor that induces autonomic neurogenesis in many other cells in the explants. Moreover, BMP2 fails to prevent expression of the sensoryspecific basic helix-loop-helix (bHLH) transcription factors neurogenin1, neurogenin2 and neuroD, although it induces expression of the autonomic-specific bHLH factor MASH1 and the paired homeodomain factor Phox2a in other cells.
These data suggest that there are mitotically active precursors in the mammalian neural crest that can generate sensory neurons even in the presence of a strong autonomic-inducing cue. Further characterization of the neurons generated from such precursors indicates that, under these culture conditions, they exhibit a proprioceptive and/or mechanosensory, but not nociceptive, phenotype. Such precursors may therefore correspond to a lineally (Frank, E. and Sanes, J. (1991) Development $111,895-908$ ) and genetically (Ma, Q., Fode, C., Guillemot, F. and Anderson, D. J. (1999) Genes Dev. 13, in press) distinct subset of early-differentiating precursors of large-diameter sensory neurons identified in vivo.

Key words: Neural crest, Sensory neurogenesis, Neurogenin, Brn3.0, BMP2, NT-3, Rat

\section{INTRODUCTION}

A fundamental question in development is how a diverse array of differentiated cell types can be produced from a multipotent population of progenitor cells. In vertebrates, this issue has been intensively investigated in the neural crest. Although a large body of evidence supports the idea that the neural crest contains multipotent progenitors whose choice of fate is determined by environmental signals, there is also evidence that the neural crest contains (or eventually generates) subsets of precursors whose fates appear restricted (for reviews see Le Douarin, 1986; Anderson, 1989; Sieber-Blum, 1990; Le Douarin et al., 1991; Marusich and Weston, 1991; Weston, 1991; Anderson, 1993; Bronner-Fraser, 1993; Le Douarin et al., 1994; Anderson, 1997). It is therefore important to understand when particular neural crest cell fates become determined in relation to others, and how lineage segregation is regulated during neural crest development.

One setting in which such issues have been addressed is in the specification of the two major neuronal classes of the peripheral nervous system (PNS), the sensory and the autonomic (Le Douarin, 1986; Sieber-Blum et al., 1993; Le Douarin et al., 1994). Clonal analyses of neural crest in vivo
(Bronner-Fraser and Fraser, 1988, 1989; Fraser and BronnerFraser, 1991) and in vitro (Sieber-Blum, 1989; Duff et al., 1991) have identified individual precursors that can give rise to both sensory and autonomic neurons. Such observations, however, do not preclude the existence of separate sensory and autonomic precursors. Previous results from back-grafting studies in avian embryos have suggested the existence of dividing precursors that can contribute to the autonomic but not sensory derivatives of the neural crest. (Le Lievre et al., 1980; Schweizer et al., 1983; Le Douarin, 1986). Whether the neural crest contains dividing progenitors that can generate sensory neurons even in the presence of autonomic-inducing cues is not known.

To better understand the mechanisms that regulate the segregation of the sensory lineage, it is necessary to be able to identify and manipulate sensory precursors, challenge them with autonomic-inducing signals and determine whether they generate sensory or autonomic neurons. Recently, several transcription factors have been characterized that can be used to identify sensory neurons and/or their precursors and distinguish them from autonomic neurons and/or their precursors. Basic helix-loop-helix (bHLH) transcription factors such as the neurogenins (ngns; Gradwohl et al., 1996; 
Ma et al., 1996; Sommer et al., 1996) and neuroD (Lee et al., 1995), as well as the POU-domain transcription factor Brn-3.0 (Fedtsova and Turner, 1995; Xiang et al., 1995) are specifically expressed in the sensory lineage. Other transcription factors are expressed by autonomic but not sensory cells, including the bHLH factor MASH1 (Johnson et al., 1990; Shah et al., 1996) and the paired homeodomain factor Phox2a (Valarché et al., 1993; Lo et al., 1998).

Members of the bone morphogenetic protein (BMP) subfamily, such as BMP2 and BMP4, have been identified as autonomic neuron-inducing signals both in vivo and in vitro. Such factors can induce autonomic differentiation in mass cultures of avian neural crest (Reissman et al., 1996; Varley and Maxwell, 1996) and in clonal cultures of mammalian neural crest stem cells (Shah et al., 1996; Shah and Anderson, 1997; Morrison et al., 1999). In the latter system, BMP2 was shown to act instructively, promoting autonomic neurogenesis from multipotent neural crest cells at the expense of other fates. Overexpression of BMP4 in ovo also induces autonomic markers in neural crest cells (Reissman et al., 1996). BMP2/4 are likely to be inducers of the autonomic fate in vivo, as they are expressed by tissues neighboring autonomic ganglia (such as the dorsal aorta; Reissman et al., 1996; Shah et al., 1996) and these tissues can mimic the inductive effects of BMPs on neural crest cells (Groves and Anderson, 1996; Reissman et al., 1996) in a manner that is inhibitable by the BMP2/4-antagonist noggin (Zimmerman et al., 1996; A. Groves and D. J. A., unpublished data).

We have now used transcription factor markers to study the development of sensory neurons in cultures of rat neural crest. We have formulated a fully defined culture medium that permits the differentiation of sensory neurons from proliferating precursors that migrate from neural tube explants. Autonomic neurons do not develop under these conditions unless they are induced to differentiate by addition of BMP2. Strikingly, BMP2 does not appear to prevent the differentiation of most dividing sensory precursors or the expression of sensory precursor markers. These data suggest that the migrating neural crest includes a subpopulation of dividing precursors that are, operationally, committed to a sensory fate with respect to the autonomic-inducing signal BMP2. Interestingly, these precursors give rise to sensory neurons that exhibit a proprioceptive and/or mechanoreceptive, rather than a nociceptive phenotype. They may therefore correspond to a distinct subset of sensory precursors previously identified by retroviral lineage tracing in chick embryos (Frank and Sanes, 1991) and more recently by genetic analyses in mice (Ma et al., 1999).

\section{MATERIALS AND METHODS}

\section{Rat neural tube explant cultures}

Neural tubes were isolated from the trunk level of E10.5 SpragueDawley rats as described previously (Stemple and Anderson, 1992) but with the following modifications: trunk sections were enzymatically treated with $1.25 \mathrm{mg} / \mathrm{ml}$ collagenase $(172 \mathrm{u} / \mathrm{mg}$, Worthingtion) and dispase $(0.77 \mathrm{u} / \mathrm{ml}$, Gibco $)$ in Hank's balanced salt solution (HBSS). The tissue was incubated for 5 minutes in ice-cold enzyme solution with trituration, then incubated for 10 minutes at room temperature, then gently triturated further until the neural tubes were free of other tissues. When neural tubes were grown in defined conditions, they were washed extensively in defined medium before plating. Explanted neural tubes were plated in $35 \mathrm{~mm}$ diameter Corning dishes on a fibronectin (BTI) substratum and grown at $37^{\circ} \mathrm{C}$ in $5 \% \mathrm{CO}_{2} / 95 \%$ air. Where stated, the neural tube was removed from the culture after 24 hours with a tungsten needle, but otherwise the explant was left intact.

\section{Media and additives \\ Defined medium}

The recipe for defined medium (DM) was modified from that described previously (Stemple and Anderson, 1992) and is as follows: to $\mathrm{L}-15 \mathrm{CO}_{2}$ (Hawrot and Patterson, 1979) add $100 \mu \mathrm{g} / \mathrm{ml}$ transferrin (Calbiochem), $5 \mu \mathrm{g} / \mathrm{ml}$ insulin (Sigma), $16 \mu \mathrm{g} / \mathrm{ml}$ putrescine (Sigma), $20 \mathrm{nM}$ progesterone (Sigma), $30 \mathrm{nM}$ selenious acid (Sigma) $1 \mathrm{mg} / \mathrm{ml}$ bovine serum albumin, (crystallized, Gibco/BRL), $39 \mathrm{pg} / \mathrm{ml}$ dexamethasone (Sigma), $5 \mu \mathrm{g} / \mathrm{ml} \alpha$-d-1-tocopherol (Sigma), $63 \mu \mathrm{g} / \mathrm{ml}$ $\beta$-hydroxybutyrate (Sigma), $25 \mathrm{ng} / \mathrm{ml}$ cobalt chloride (Sigma), 1 $\mu \mathrm{g} / \mathrm{ml}$ biotin (Sigma), $10 \mathrm{ng} / \mathrm{ml}$ oleic acid (Sigma), $3.6 \mathrm{mg} / \mathrm{ml}$ glycerol, $100 \mathrm{ng} / \mathrm{ml} \alpha$-melanocyte-stimulating-hormone (Sigma), 10 $\mathrm{ng} / \mathrm{ml}$ prostaglandin E1 (Aldrich). Basic fibroblast growth factor (bFGF; $10 \mathrm{ng} / \mathrm{ml}, \mathrm{UBI}$ ) was included in the medium for the first 2 days, but not thereafter. Where indicated, DM was supplemented with recombinant human BMP2 (50 ng/ml, gift from Genetics Institute).

\section{Undefined medium}

Undefined medium was also modified from that described previously (Stemple and Anderson, 1992). It contained the same basal components as the DM described above plus bFGF (4 ng/ml, R\&D Systems Inc.), epidermal growth factor (EGF; $100 \mathrm{ng} / \mathrm{ml}$, Sigma), retinoic acid (35 ng/ml, Sigma), nerve growth factor (NGF; $50 \mathrm{ng} / \mathrm{ml}$, $\mathrm{UBI}$ ), brain-derived growth factor (BDNF; $25 \mathrm{ng} / \mathrm{ml}$ ), neurotrophin3, (NT3; $25 \mathrm{ng} / \mathrm{ml}$, BDNF and NT3 both provided by Dr G. Yancopoulos at Regeneron Pharmaceuticals), leukemia inhibitory factor (LIF; $25 \mathrm{ng} / \mathrm{ml}, \mathrm{R} \& \mathrm{D}$ Systems Inc.) and 10\% chick embryo extract (CEE) for the first 24 hours, $0.1 \%$ CEE thereafter.

\section{Immunocytochemistry}

Cultures were fixed in $4 \%$ paraformaldehyde and then processed for single or double antibody labeling or in situ hybridization (see below) followed by antibody labeling. Antibody-antibody double labeling involved detection of antigens using NiDAB and DAB substrates as described previously (Shah et al., 1994). Finally, cultures were incubated with $10 \mu \mathrm{g} / \mathrm{ml}$ DAPI for 15 minutes at room temperature to identify other nuclei and thus the extent of the outgrowth from the neural tube.

Primary antibody incubations were carried out at $4{ }^{\circ} \mathrm{C}$ overnight. Affinity-purified rabbit anti-Brn-3.0 antibody (1:500; Fedtsova and Turner, 1995) and hamster anti-DRG11 hybridoma supernatant (Saito et al., 1995) were used to detect sensory neurons. Monoclonal antibodies to SCG10 (hybridoma supernatant; L. Lo and D. J. A., unpublished data), neurofilament 160 (1:250; NF160, clone NN18, Sigma), or NeuN (1:500, Chemicon) were used as general neuronal markers. Peripheral neurons were identified using the combination of Brn-3.0 expression and polyclonal anti-peripherin (1:2000; Chemicon) or monoclonal anti-c-RET (hybridoma supernatant; Lo and Anderson, 1995) antibodies. Rabbit polyclonal anti-Phox2a antibody (1:5000; gift from Drs. C. Goridis and J. F. Brunet; Tiveron et al., 1996) was used to identify autonomic cells. Autonomic precursors were stained using anti-MASH1 hybridoma supernatant (Lo et al., 1991). The monoclonal antibody RT97 (1:500; gift from Dr J. N. Wood; Lawson et al., 1984) and rabbit polyclonal anti-ER81 antibody $(1: 12,000$; gift from Dr T. Jessell; Lin et al., 1998) were used as markers of the large, proprioceptive subtype of sensory neurons. Rabbit polyclonal antibodies to Substance P (SP; 1:1000; Incstar), calcitonin gene related peptide (CGRP; 1:1000; Peninsula Laboratories, Inc.) and TrkA (1:500; gift from Dr L. Reichardt; Clary et al., 1994) were used as markers of the small nociceptive sensory subtype. 
All secondary antibodies were used at a dilution of 1:200 and incubated for 1 hour at room temperature. Rabbit polyclonal antibodies were detected using an HRP-conjugated, goat anti-rabbit secondary antibody purchased from Vector Labs, Inc.. The monoclonal antibodies to SCG10, NF160 and MASH1 were detected with an HRP-conjugated, goat anti-mouse IgG secondary from Chemicon. Hamster monoclonal antibodies to c-RET and DRG11 were detected by a biotinylated goat anti-mouse IgG secondary antibody (Jackson Laboratories, Inc.) followed by the $\mathrm{ABC}$ amplification system (Vectastain ABC kit, Vector Labs, Inc.).

\section{In situ hybridization}

In situ hybridization on explants was performed using a modification of procedures developed by Dr R. Li (Signal Pharmaceuticals, personal communication) and Dr D. Henrique (Henrique et al., 1995). Briefly, the explants were pretreated with acetic anhydride and $0.2 \mathrm{~N}$ $\mathrm{HCl}$ then prehybridized for 1 hour at room temperature. Hybridization in $1-2 \mu \mathrm{g} / \mathrm{ml}$ of digoxigenin (DIG)-labeled probe was carried out at $65^{\circ} \mathrm{C}$ overnight. After the hybridization, explants were washed at high stringency $\left(0.2 \times \mathrm{SSC}\right.$ at $65^{\circ} \mathrm{C}$ for 1 hour $)$, incubated with alkaline phosphatase (AP)-conjugated anti-digoxigenin antibody (Boehringer) and the signal developed using NBT/BCIP reagents. A more detailed protocol is available upon request. The probes used in this study include rat $n g n 1$ (Ma et al., 1996), mouse $n g n 2$ (Sommer et al., 1996) and mouse neuroD (Lee et al., 1995). For in situ antibody double labeling, explants were processed first for in situ detection of mRNA, then for immunocytochemistry as described above.

\section{BrdU analysis}

To determine the mitotic status of sensory precursors in vitro, explants were grown in DM and supplemented with $175 \mathrm{nM} \mathrm{BrdU}$ at the time of plating (day 0) or after 1, 2 or 3 days of culture. After initial crest migration ( 24 hours), explants were modified by removing the neural tube from culture with a tungsten needle. Cultures were grown in the presence of BrdU for 24 hours, then fixed and processed for fluorescent Brn-3.0/BrdU double labeling. Rabbit anti-Brn-3.0 antibody (see above) was detected using a FITC-conjugated goat antirabbit secondary from Jackson Laboratories. After Brn-3.0 staining, BrdU incorporation was detected as described previously (Novitch et al., 1996) using a mouse anti-BrdU primary antibody (1:100, Caltag) and Cy5-conjugated goat anti-mouse secondary antibody (1:200, Jackson). Staining was observed using a 410 Ziess Axiovert LSM confocal microscope. Double-positive nuclei were scored by identifying individual Brn-3.0 $0^{+}$cells in one channel (green) and checking for an identically shaped, BrdU ${ }^{+}$nucleus in the other channel (red). In cases where it was not possible to clearly determine if a Brn- $3.0^{+}$cell had incorporated BrdU, these cells were omitted from the analysis; this situation occurred most often when the cells were tightly clustered in explants at day 1 .

\section{Trophic support analysis}

Neural crest explants were cultured in DM supplemented with 10 $\mathrm{ng} / \mathrm{ml}$ bFGF for 2 days. On day 3, DM (without bFGF) was supplemented with growth factors singly or in combination at the following concentrations: NGF (100 ng/ml), BDNF (50 ng/ml), NT3 $(50 \mathrm{ng} / \mathrm{ml})$ and/or LIF $(50 \mathrm{ng} / \mathrm{ml})$. The medium and factors were replaced every 2-3 days until the explants were fixed at day 8 and processed for Brn-3.0 antibody staining. The number of Brn-3.0 $0^{+}$cells in the dorsal outgrowth was scored for each explant, excluding cells tightly associated with the neural tube.

\section{RESULTS}

\section{Both sensory and autonomic neurons are generated in rat neural tube explant cultures}

To characterize the types of neurons that differentiated in rat

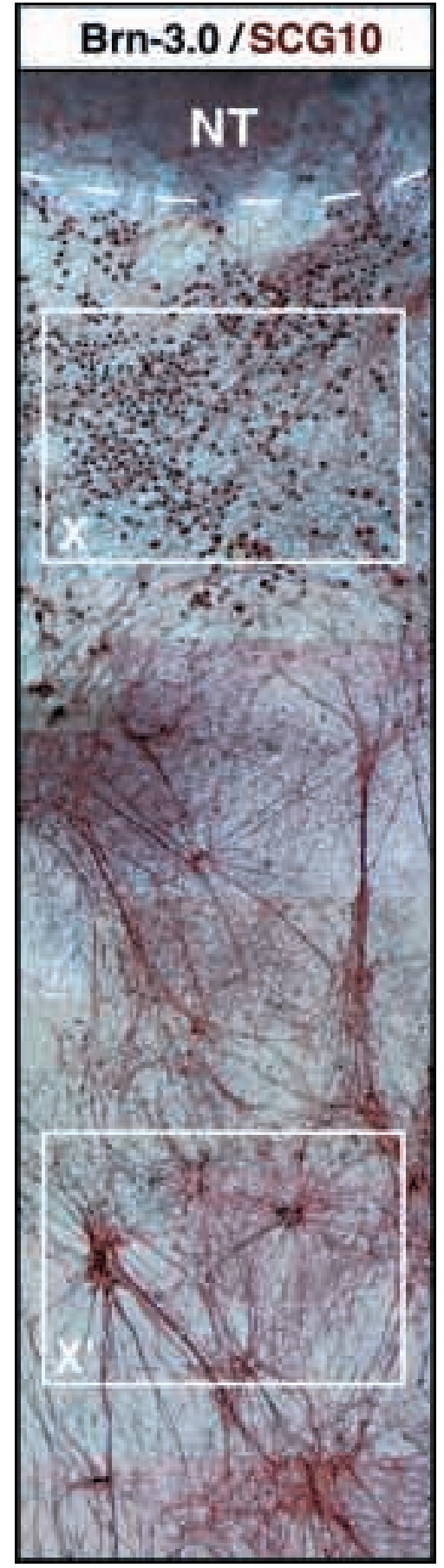

Fig. 1. Two populations of neurons develop in rat neural tube explant cultures. The view shown includes the dorsal neural tube (NT, top) and neural crest outgrowth (below dashed line) of an explant grown for 8 days in CEEcontaining medium plus NGF, BDNF, NT3 and LIF. The explant is stained for both Brn-3.0 (dark blue, nuclear) and SCG10 (brown,

cytoplasmic) via immunocytochemistry. Brn- $3.0^{+} / \mathrm{SCG} 10^{+}$cells are located in the outgrowth proximal to the neural tube and have large cell bodies (region $\mathrm{X}$ ). Brn-3.0-/SCG10 ${ }^{+}$cells are smaller and often found in clusters in the periphery of the outgrowth (region $\mathrm{X}^{\prime}$ ). The punctate staining in this latter region represents perinuclear SCG10 and not nuclear Brn-3.0 staining; see Fig. $2 \mathrm{~B}^{\prime}-\mathrm{D}^{\prime}$ for higher magnification images showing that the neurons in this region do not express Brn-3.0.

neural tube explant cultures, we examined the expression of lineage-specific transcription factor markers in combination with general markers of peripheral neurons (Table 1). Both Brn-3.0, a POU-domain transcription factor, and DRG11, a paired homeodomain factor, are expressed by sensory but not autonomic neurons in the PNS in vivo (Fedtsova and Turner, 1995; Saito et al., 1995). Moreover, Brn-3.0 is genetically important for some aspects of sensory neuron development (McEvilly et al., 1996; Xiang et al., 1996). Although these transcription factors are also expressed by dorsal spinal cord neurons, Brn-3.0 $0^{+}$or DRG11 ${ }^{+}$peripheral sensory neurons can be distinguished from these CNS neurons by their expression 


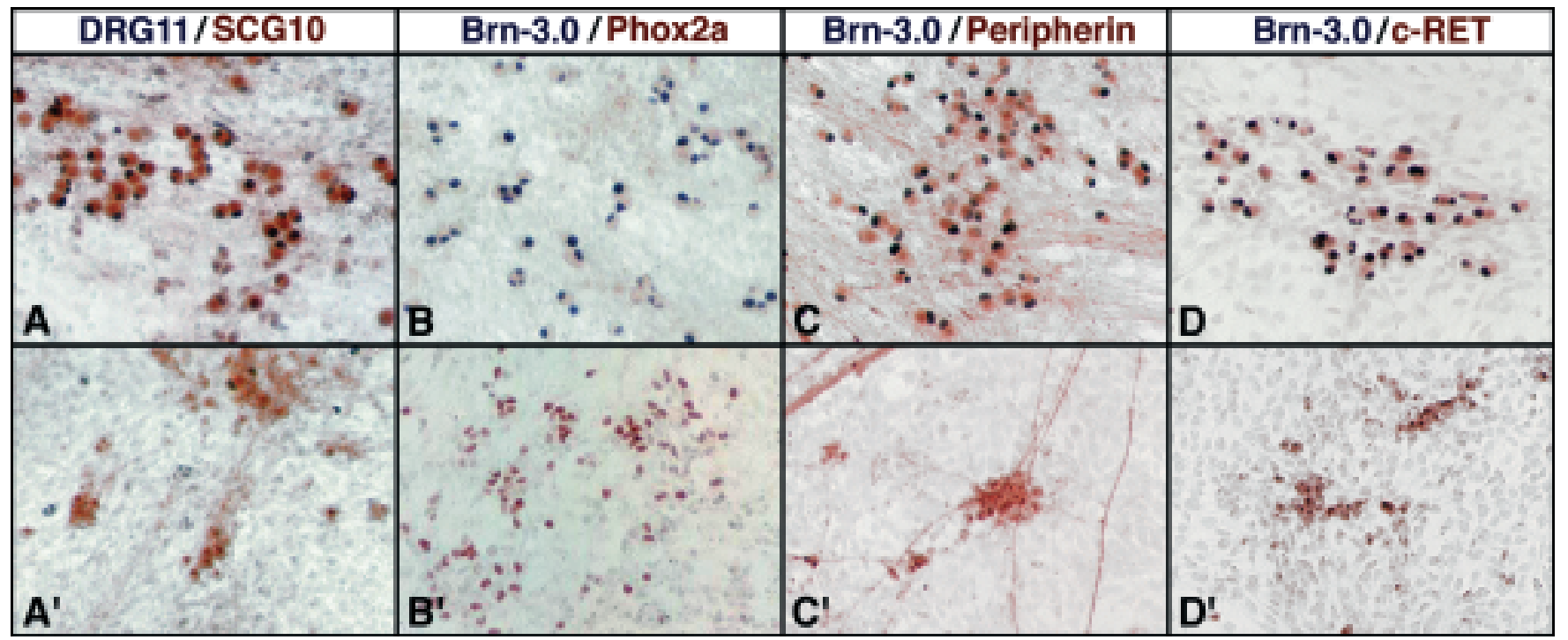

Fig. 2. Neural tube explant cultures contain peripheral sensory and autonomic neurons. Double-immunocytochemistry shows that largediameter cells in the neural tube-proximal region of the outgrowth (Fig. 1, region X) express the sensory markers DRG11 (A) and Brn-3.0 (BD; dark blue, nuclear). They also express SCG10 (A), peripherin (C) and c-RET (D; brown, cytoplasmic). Smaller-diameter cells in the same

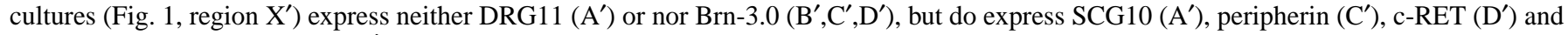
the autonomic marker Phox2a ( $\mathrm{B}^{\prime}$; brown, nuclear).

of peripherin (Parysek and Goldman, 1988) or c-RET (Pachnis et al., 1993). Peripheral autonomic neurons can be identified by their expression of the paired homeodomain factor Phox2a (Valarché et al., 1993; Tiveron et al., 1996) and either peripherin or c-RET, as well as by their lack of sensory markers (Table 1).

We first applied this array of markers to neural tube explants grown for 8 days in standard CEE-containing ('undefined') medium supplemented with the neurotrophic factors NGF, LIF, BDNF and NT3 (see Materials and Methods). Two populations of morphologically and antigenically distinct neurons were evident in the outgrowth of these cultures. Brn-3.0 ${ }^{+} / \mathrm{SCG} 0^{+}$ neurons had large somata and tended to be located proximal to the neural tube (Fig. 1X). Neurons in this location also expressed DRG11 (Fig. 2A), peripherin (Fig. 2C) and c-RET (Fig. 2D). We conclude that the large, neural tube-proximal neurons are sensory in nature. It was not possible to double-

Table 1. Marker combinations identify peripheral sensory and autonomic neurons

\begin{tabular}{|c|c|c|c|c|c|}
\hline & Brn-3.0 & $\mathrm{DRG} 11^{\mathrm{b}}$ & Phox $2 a^{c}$ & c-RET ${ }^{d}$ & Peripherin $^{\mathrm{e}}$ \\
\hline \multicolumn{6}{|l|}{ PNS } \\
\hline sensory neurons & + & + & - & + & + \\
\hline autonomic neurons & - & - & + & + & + \\
\hline \multicolumn{6}{|l|}{$\mathrm{CNS}$} \\
\hline dorsal neural tube & + & + & - & - & - \\
\hline $\begin{array}{l}\text { preganglionic } \\
\text { autonomic neurons }\end{array}$ & n.d. & n.d. & + & - & - \\
\hline motor neurons & - & - & - & + & + \\
\hline \multicolumn{6}{|c|}{$\begin{array}{l}\text { The table summarizes previously published expression data in the rodent } \\
\text { embryo at trunk level. (a) Fedtsova and Turner, 1995; Xiang et al., } 1995 . \\
\text { (b) Saito et al., 1995. (c) Valarché et al., 1993; Tiveron et al., } 1996 . \\
\text { (d) Pachnis et al., 1993; Lo and Anderson, 1995. (e) Parysek and Goldman, } \\
\text { 1988. (+) expression in tissue indicated. (-) no expression in tissue indicated. } \\
\text { (n.d.) not determined. }\end{array}$} \\
\hline
\end{tabular}

label such neurons for Brn-3.0 and Phox2a (Fig. 2B, B') because the chromogen used to visualize Brn-3.0 labeling obscured that used for Phox2a. However, in cultures labeled only for Phox $2 \mathrm{a}$, the neurons with large cell bodies located proximal to the neural tube generally did not express the autonomic marker (data not shown).

A separate population of smaller neurons was observed scattered throughout the outgrowth, often found in tight clusters in the periphery (Fig. $1 \mathrm{X}^{\prime}$ ). These smaller neurons did

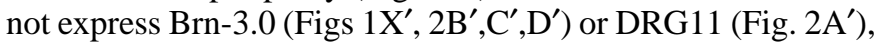

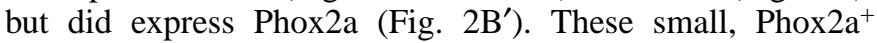
neurons expressed peripherin (Fig. 2C, $\mathrm{C}^{\prime}$ ) and c-RET (Fig. $\left.2 \mathrm{D}, \mathrm{D}^{\prime}\right)$, indicating a peripheral, autonomic phenotype. Thus, the use of specific transcription factor markers indicates that neurons of both sensory and autonomic lineages are generated in neural tube explant cultures grown in CEE-containing medium. Qualitatively, many more autonomic than sensory neurons appeared to develop under these conditions. It is striking that the sensory and autonomic neurons in these explants are located proximal and distal to the neural tube, respectively, as are sensory and autonomic derivatives in vivo.

\section{Defined medium permits sensory but not autonomic neurogenesis}

A previous study suggested that the differentiation of sensory neurons may be promoted by growth in defined medium lacking serum or CEE (Ziller et al., 1987). We therefore formulated a defined medium (DM) with the intention of determining the growth requirements of sensory and autonomic neurons in the absence of CEE (see Materials and Methods). When neural tube explants were grown for 4 days in such DM, greater than $95 \%$ of the neurons in the outgrowth were Brn$3.0^{+}$as determined by double labeling for Brn-3.0 and $\mathrm{NeuN}$, a pan-neuronal marker (data not shown). The Brn-3.0 $0^{+}$cells had a neuronal morphology, expressed NF160 (Fig. 3A, inset) 


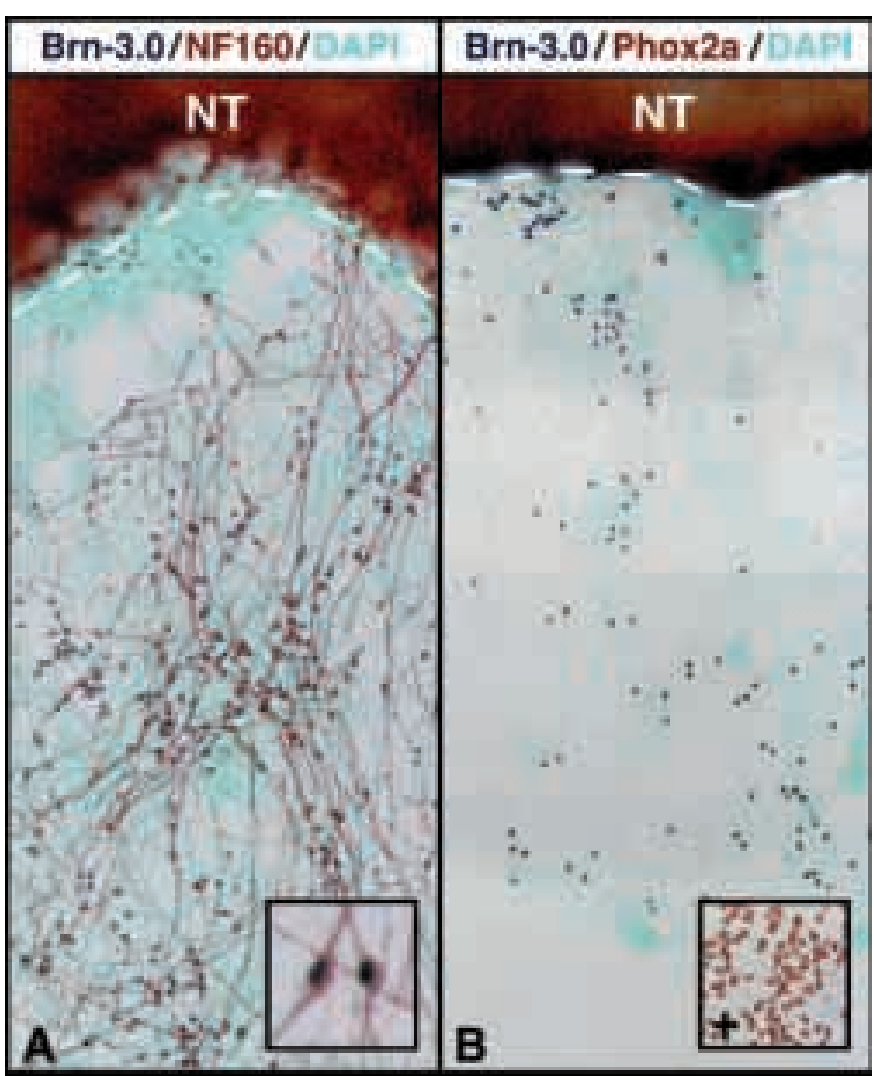

Fig. 3. Defined medium supports sensory but not autonomic neuronal differentiation. (A,B) Cells stained with an antibody to Brn-3.0 (dark blue, nuclear) are found in the crest outgrowth of explants grown for 4 days in defined medium. The cultures in (A) have been counterstained with an antibody to NF160 (brown filamentous staining). The dashed line divides the neural tube (NT, top) and the outgrowth (below dashed line). (A, inset) Brn-3.0+ cells co-express NF160 (brown, cytoplasmic; see also Fig. 4). (B) Cells in the outgrowth of these explants are not labeled with an antibody to Phox2a (brown, nuclear). Phox2a staining on BMP2-treated cultures (see also Fig. 6) serves as a positive control (inset in B). Unlabeled cells are visualized with DAPI fluorescence (aqua, nuclear).

and peripherin (data not shown), and made up $6.6 \pm 2.8 \%$ of cells in the outgrowth. In contrast, autonomic (Brn-3.0-/ Phox $\left.2 \mathrm{a}^{+}\right)$cells were almost never observed under these conditions $(0.06 \pm 0.12 \%$ of cells in the outgrowth, Fig. 3B). Thus, this DM was permissive for sensory but not autonomic neuronal differentiation. The sensory neurons in DM cultures were not restricted to any particular region along the proximodistal axis of the outgrowth, in contrast to CEEcontaining cultures where they were located proximal to the neural tube.

\section{Sensory neurons differentiate de novo from migratory precursors}

It was formally possible that the sensory neurons that we observed in vitro did not differentiate de novo, but derived from already-differentiated neurons that simply migrated onto the culture substratum. To address this possibility, we compared the expression of Brn-3.0, which is found in both sensory precursors and sensory neurons (Fedtsova and Turner, 1995; Xiang et al., 1995), to that of NF160, an early marker of
Fig. 4. Sensory precursors differentiate into neurons by day 2-3 in defined medium. (A-C) Double-labeling for Brn-3.0 (dark blue, nuclear) and NF160 (brown, cytoplasmic) antigens shows that after 1 day of culture, few Brn-3.0 $0^{+}$cells in the neural crest outgrowth co-express NF160 (A, arrow). When this outgrowth (minus neural tube) is cultured until day 2 (B) or day 3 (C), a majority of Brn3. $0^{+}$cells co-express NF160. (D) The graph indicates the average number of Brn-3.0 $0^{+}$ cells per explant at each day, divided into Brn3. $0^{+} / \mathrm{NF} 160^{-}$(blue part of bar) and Brn3. $0^{+} / \mathrm{NF} 160^{+}$(brown part of bar) fractions. Note that as the total number of Brn-3.0 $0^{+}$ cells per explant increases from day 1 to day 2 , the proportion of these cells that express NF160 increases as well. (n) is the number of explants scored from two experiments. Error bars represent standard deviations.

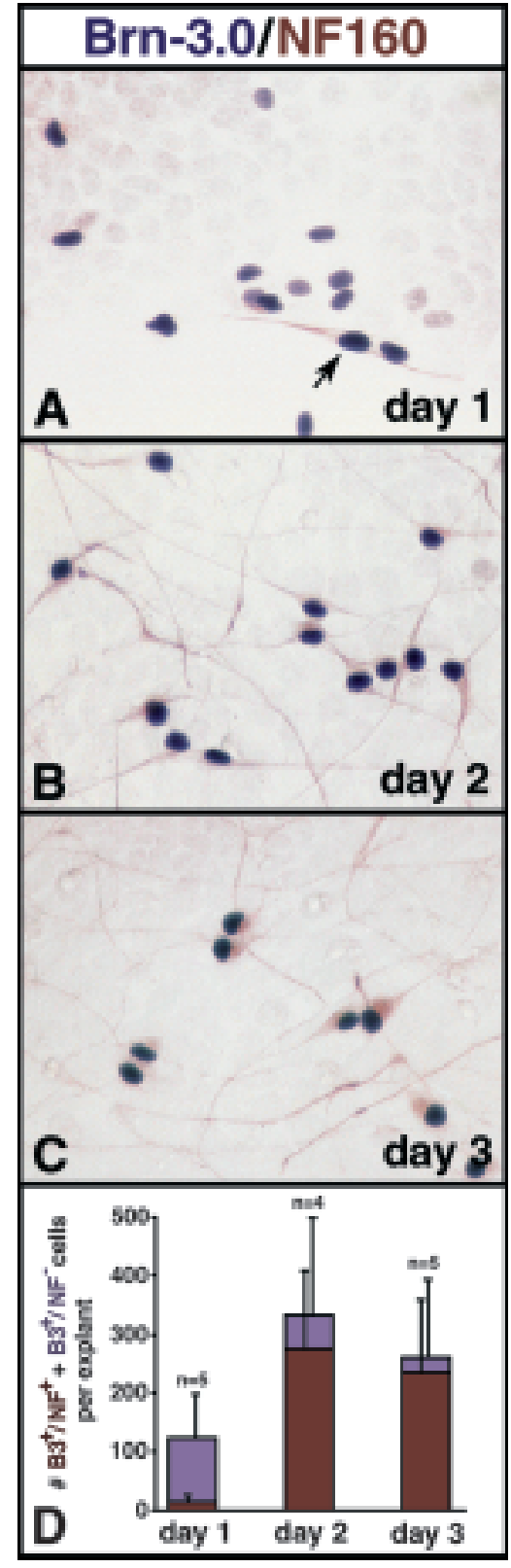

neuronal differentiation. In cultures grown for 24 hours in DM, only a minority of the Brn-3.0 $0^{+}$cells that had migrated onto the substratum co-expressed NF160 (Fig. 4A,D). However, when such 24 hour outgrowth was cultured for an additional day following removal of the neural tube (to prevent the emigration of additional precursors), most of the Brn-3. $0^{+}$cells co-expressed NF160 and had acquired a neuronal morphology (Fig. 4B,D). By day 3, no further increase in NF160 expression was apparent, although the neuronal somata appeared larger (Fig. 4C,D). The increase in the percentage of Brn-3.0 $0^{+}$cells that co-expressed NF160 between day 1 and day 2 did not appear to be due to the selective death of undifferentiated Brn$3.0^{+} / \mathrm{NF} 160^{-}$cells, since the average number of Brn-3.0 $0^{+}$cells per explant increased, rather than decreased, during that time period (Fig. 4D). These data suggest that the Brn-3.0 $0^{+} / \mathrm{NF} 160^{+}$ sensory neurons in these explants differentiate de novo from Brn-3.0 $/ \mathrm{NF}^{+} 60^{-}$precursors between day 1 and day 2 of 
culture. Such differentiation can occur in a fully defined medium lacking exogenously supplied neurotrophic factors.

\section{Sensory neurons develop from dividing precursors}

We were interested to determine whether the sensory precursors in our cultures divided prior to differentiating. Previous studies have reported that the sensory neurons that differentiate rapidly in neural crest cultures are derived from postmitotic precursors (Ziller et al., 1983, 1987; Matsumoto, 1994b). To determine the mitotic activity of the sensory precursors found in our cultures, explants were exposed to 24hour pulses of $175 \mathrm{nM}$ BrdU beginning at the time of plating (day 0 ), or at day 1, day 2 or day 3 . Immediately after the pulse, the cells were fixed and processed for Brn-3.0/BrdU double immunofluorescence. Again, the neural tube was removed from the cultures after 24 hours to avoid the influx of new precursors into the outgrowth.

Surprisingly, when BrdU was applied at the time of plating, greater than $95 \%$ of the Brn- $3.0^{+}$cells in the outgrowth had incorporated the analog by the end of day 1 (Fig. 5A,E). During the next day (day 1-2), BrdU was incorporated into approximately $50 \%$ of Brn- $3.0^{+}$cells (Fig. $5 \mathrm{~B}, \mathrm{E})$. The percentage of $\mathrm{BrdU}^{+} / \mathrm{Brn}-3.0^{+}$cells dropped dramatically on subsequent days of incubation: less than 5\% of Brn-3. $0^{+}$cells were labeled with BrdU when it was applied during day 2-3 (Fig. 5C,E), and there was essentially no labeling when it was applied during day 3-4 (Fig. 5D,E). These results indicate that most sensory precursors in our cultures are mitotically active as they leave the neural tube. Moreover, many of these cells divide during the subsequent day in culture. After two days, most of the sensory precursors have become postmitotic.

\section{BMP2 does not prevent either dividing or postmitotic precursors from executing a sensory fate}

If the sensory and autonomic neurons that differentiate in explant cultures (Figs 1,2) arise from a common precursor, conditions that promote differentiation of autonomic neurons might do so at the expense of sensory neurons. To explore this possibility, we challenged sensory precursors with $50 \mathrm{ng} / \mathrm{ml}$ of BMP2, a signal that instructs some neural crest precursors to become autonomic neurons at the expense of other cell fates (Shah et al., 1996; Shah and Anderson, 1997; Morrison et al., 1999). After removal of the neural tube at 24 hours, BMP2 was applied during the second day, a period during which similar cultures grown in DM contain many dividing sensory precursors (see Figs 4A, 5B,E, respectively). Following a 24 hour exposure of such cultures to BMP2, a vast number of cells expressed Phox2a (Fig. 6B, brown nuclei), approximately 5- to 10 -fold more than the number of cells expressing Brn-3.0. Thus, although cultures grown in DM do not contain autonomic neurons, treatment of such cultures with BMP2 reveals a large population of neural crest cells with autonomic capacity. Despite this huge induction of autonomic neurogenesis by BMP2, the percentage of Brn-3.0 $0^{+}$neurons per explant did not differ significantly when cultures were grown in the absence (Fig. 6A,C) or presence (Fig. 6B,C) of the factor. Furthermore, the exposure of explants to BMP2 did not seem to affect the total number of Brn-3.0 $0^{+}$cells per explant ( $z=0.995$, Mann-Whitney U-test, data not shown). These data suggest that the sensory precursors present in these cultures cannot be diverted to an autonomic fate by BMP2, although this factor clearly induces autonomic neurogenesis in many other cells in the explants.

As shown above, approximately $50 \%$ of the Brn-3.0 $0^{+}$cells in cultures grown in DM come from precursors that divided between day 1 and day 2. (see Fig. 5B,E). Although BMP2 did not drastically reduce the percentage or number of Brn-3. $0^{+}$ cells per explant, the scatter in the data might conceal the inhibition by BMP2 of sensory differentiation from a subset of dividing precursors. When BMP2-treated cultures were labeled with BrdU during day 2, however, we found that the factor did not prevent the differentiation of Brn-3.0 $0^{+}$neurons from
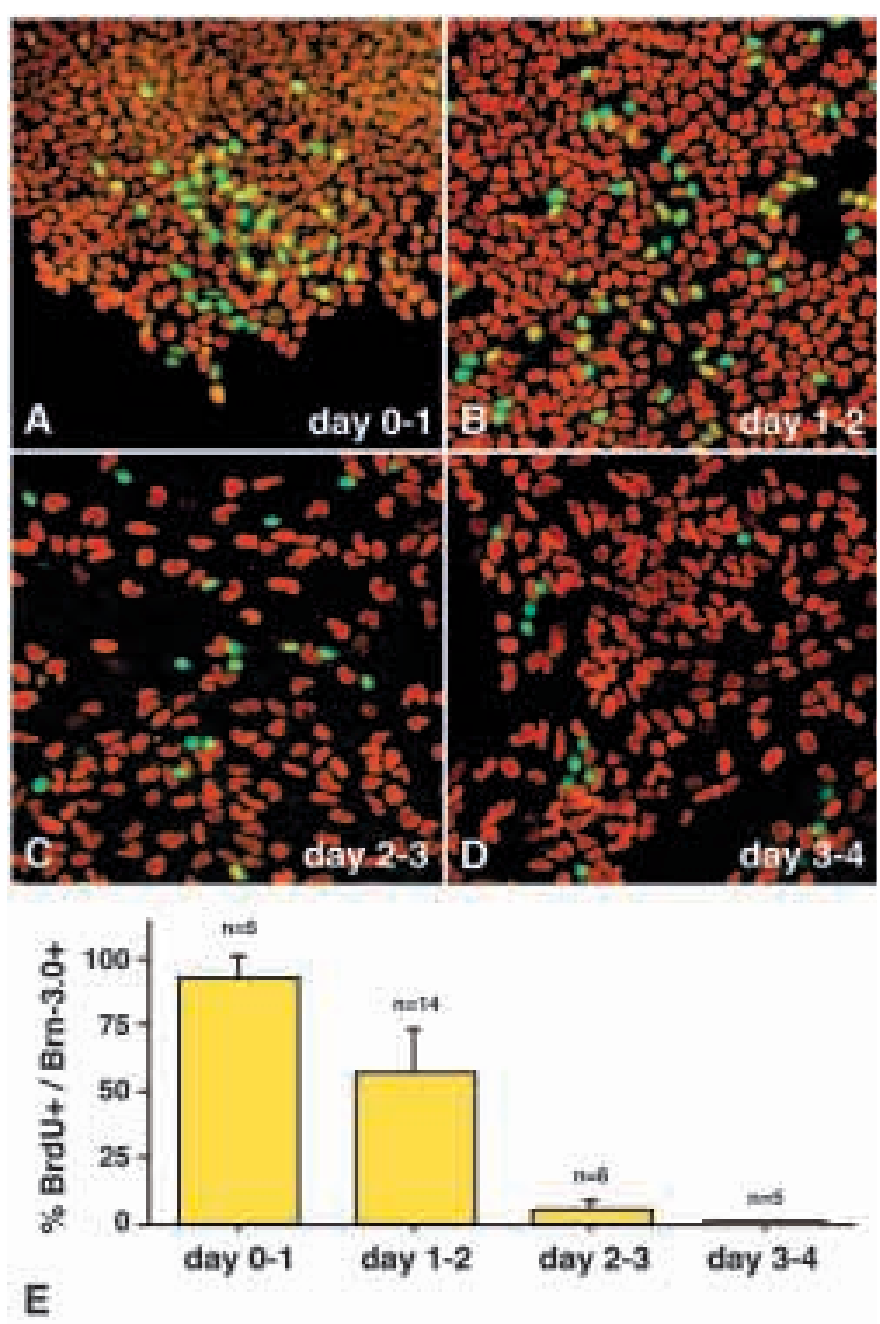

Fig. 5. Sensory precursors divide during the first two days of culture. (A-D) Confocal images show Brn-3.0 (green) and BrdU (red) double-immunofluorescence in cultures of neural crest outgrowth pulsed with BrdU for 24 hours at either the time of plating at day 0-1 (A), from day 1-2 (B), day 2-3 (C) or day 3-4 (D). Strongly doublelabeled cells appear yellow. (E) The percentage of Brn-3.0 $0^{+}$cells that incorporated BrdU during the previous 24 hours was quantitated per explant and is represented as an average. $\mathrm{n}$ is the number of explants from 2-3 experiments, error is given as standard deviation. Note that the high percentage of Brn-3. $0^{+}$cells labeled by BrdU at day $0-1$ and 1-2 is consistent with the more than doubling in the total number of Brn-3.0 $0^{+}$cells per explant during this period (Fig. 4D). 
Fig. 6. BMP2 induces Phox2a but does not prevent expression of Brn-3.0 or division of sensory precursors. $(\mathrm{A}, \mathrm{B})$ Double labeling for Brn-3.0 and Phox2a at day 2 indicates that Brn-3.0 $0^{+}$cells (dark blue, nuclear) are present in cultures of neural crest outgrowth which have been grown for 24 hours in either the absence (A) or presence (B) of BMP2. Phox $2 \mathrm{a}^{+}$cells (brown, nuclear) are only found in BMP2-treated cultures (B). Unlabeled cells are visualized with DAPI fluorescence (aqua nuclei in A,B). Note that the massive induction of Phox 2a by BMP2 in 24 hours is unlikely to be explained by the selective survival or proliferation of a subset of Phox $2 \mathrm{a}^{+}$ cells present in control cultures; therefore BMP2 is likely to act instructively rather than selectively. (C) Quantitation of the average percentage of Brn-3.0 $0^{+}$ expression per explant at day 2, after 24 hours of growth in 'No Add' or in $50 \mathrm{ng} / \mathrm{ml} \mathrm{BMP2}$. The data show that there is no statistically significant reduction in the percentage of Brn-3. $0^{+}$cells by BMP2 ( $P=0.705, t$-test $)$. Similar results were obtained when the total number of Brn-3.0 $0^{+}$cells per explant, rather than the percentage of Brn-3.0 $0^{+}$cells per explant, was scored (not shown). (D) The average percentage of BrdU incorporation into Brn-3.0 $0^{+}$cells per explant decreases slightly, but significantly ( $* P=0.004, t$-test), in the presence of BMP2. In C and D, $n$ is the number of explants counted over 3 experiments; error is represented as standard deviation.

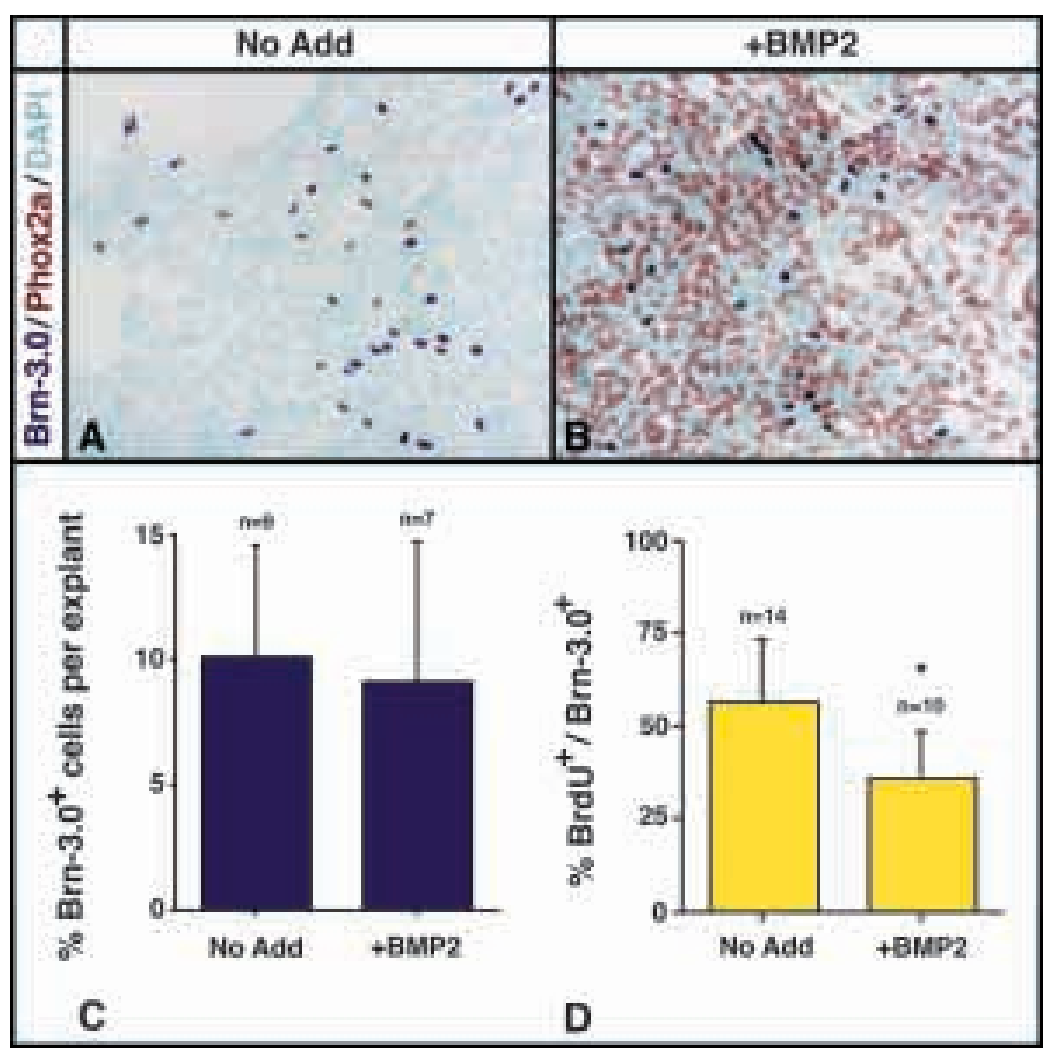

dividing precursors, although it did reduce slightly (by about $35 \%$ ) the proportion of Brn- $3.0^{+}$cells labeled by BrdU (Fig. $6 \mathrm{D})$. These data suggest that the majority of dividing sensory precursors in these cultures cannot be respecified by an autonomic neuron-inducing signal. The slight decrease in the percentage of Brn-3.0 $0^{+}$cells that incorporated BrdU could indicate that BMP2 either promotes cell cycle arrest in a minority of sensory precursors, kills some of the cycling precursors, or else diverts a small subpopulation of them to an autonomic fate.

\section{Identification of neural crest cells expressing early sensory precursor-specific markers}

The previous data indicated that neural tube explants grown in DM contain a population of mitotically active sensory neuron precursors that cannot be diverted to an autonomic fate by exposure to BMP2 during the second day of culture. However, these data did not exclude the possibility that more immature sensory progenitors, such as those that do not yet express Brn3.0, may be respecified by the factor. We therefore sought to directly visualize such precursors in order to examine their response to BMP2. To do this, we used the bHLH transcription factors $n g n 1$, ngn2 and neuroD as early markers of sensory precursors. In vivo, ngn2 is transiently expressed by some migrating crest cells, while ngnl is expressed slightly later following condensation of the sensory ganglia (Sommer et al., 1996; Perez et al., 1999; Ma et al., 1999). neuroD expression is downstream of and genetically dependent on the ngns (Ma et al., 1996, 1998; Fode et al., 1998). Expression of neuroD appears to overlap the period during which Brn-3.0 is expressed during DRG formation in vivo (Fedtsova and Turner, 1995).

In situ hybridization of 24 hour explant cultures revealed cells expressing $n g n 2$ mRNA both in the neural tube and in the immediately adjacent outgrowth (Fig. 7B,E, arrows). Combined in situ hybridization and antibody staining indicated that most of the $n g n 2^{+}$cells in the outgrowth did not co-express Brn-3.0 (Fig. 7E, arrowheads), although a few examples of $n g n 2^{+} /$Brn $-3.0^{+}$cells could be found (Fig. 7E, inset). This relative lack of overlap is consistent with the fact that expression of $n g n 2$ is initiated prior to that of Brn-3.0 in vivo (Fedtsova and Turner, 1995; Sommer et al., 1996; Ma et al., 1999), but the identification of double-labeled cells supports the idea that at least some Brn- $3.0^{+}$sensory neurons derive from ngn2-expressing precursors (see below). Expression of ngnl was not detected among emigrating crest cells in such 24 hour explants (Fig. 7A), but was detected a day later (Fig. 8C), consistent with the fact that its expression follows that of $n g n 2$ in vivo (Sommer et al., 1996; Ma et al., 1999).

Numerous neuroD ${ }^{+}$cells were also found throughout the outgrowth (Fig. 7C,F arrows) as well as in the neural tube (data not shown). The neuroD ${ }^{+}$cells in the outgrowth tended to be located more distal to the neural tube than $n g n 2^{+}$cells (Fig. $7 \mathrm{~B}, \mathrm{C})$, suggesting that the neuro ${ }^{+}$cells may have emigrated early and have already downregulated expression of $n g n 2$ (Lee et al., 1995; Ma et al., 1996, 1998; Fode et al., 1998). In contrast to ngn2, most neuroD ${ }^{+}$cells co-expressed Brn-3.0 $0^{+}$ (Fig. 7F, arrows and arrowheads; inset). Given the genetic dependence of neuroD expression on $n g n 2$, the $n g n 2^{+} / \mathrm{Brn}-3.0^{-}$ and the neuro $D^{+} / \mathrm{Brn}-3.0^{+}$precursors likely represent successive stages in sensory development. Consistent with this, forced expression of ngns can induce expression of Brn-3.0 both in vivo (S. Perez and D. J. A., unpublished data) and in vitro (L. Lo and D. J. A., unpublished data). Thus expression of $n g n s$ can be used to identify sensory precursors at an even 
earlier stage than they can be identified by expression of Brn3.0.

\section{BMP2 does not prevent expression of early, sensory precursor-specific markers}

To determine if BMP2 might prevent the development of the early sensory precursors identified by expression of $n g n 2$ or neuroD, we exposed explants to this factor at the time of plating (before neural crest emigration) and assayed expression of these and other markers after 24 hours. Although BMP2 induced expression of both Phox $2 \mathrm{a}$ and MASH1 in the outgrowth of neural tube explants (Fig. 8F,G, arrows, compare Fig. $8 \mathrm{~A}, \mathrm{~B})$, it did not abolish the expression of $n g n 1, n g n 2$ and neuroD in cells adjacent to the neural tube (Fig. 8H-J). If anything, the expression of these sensory precursor-specific genes in the explants may have been slightly elevated by exposure to BMP2 (Fig. 8, compare C versus $\mathrm{H}$, D versus I, E versus J). As expected from the results described earlier, addition of BMP2 at the time of plating also did not prevent the expression of Brn-3.0 (Fig. 8A,F, arrowheads). These data indicate, qualitatively, that the survival and/or proliferation of early sensory precursors identified by expression of $n g n s$ and neuroD was not prevented by addition of BMP2, and that the factor did not suppress expression of these sensory bHLH genes. Moreover, as ngn2 is expressed earlier than Brn-3.0, these results suggest that sensory precursors may be refractory to the autonomic-inducing activity of BMP2 even before they express Brn-3.0.

Strikingly, the MASH1 ${ }^{+}$autonomic precursors revealed by addition of BMP2 occupied a more distal region of the outgrowth relative to the neural tube than did the sensory precursors identified by expression of the ngns (cf. Fig. 8G, arrows versus $8 \mathrm{H}, \mathrm{I}$ and $\mathrm{J}$ ). This complementary distribution is similar to that of the differentiated sensory and autonomic neurons that develop from these precursors (Fig. 1, compare X versus $\mathrm{X}^{\prime}$, Fig. 8F, compare arrowheads versus arrows). The reasons for this patterned distribution are unclear but are currently under investigation.

\section{The phenotype of sensory neurons generated in defined medium includes the proprioceptive and/or mechanoreceptive, but not nociceptive, sensory subtypes}

The relative rapidity with which the Brn-3.0 $0^{+}$sensory neurons developed in our cultures suggested that they may correspond to the early-differentiating subset of sensory neurons in vivo. Early-differentiating neurons are large-diameter cells that comprise primarily the proprioceptive and mechanoreceptive sensory subtypes (Lawson et al., 1974; Lawson and Biscoe, 1979; Lawson, 1992). We were therefore interested in defining the subtype(s) of the sensory neurons that differentiate in our cultures. Since it is known that different subsets of sensory neurons require specific neurotrophins for their survival (reviewed in Snider, 1994), we sought to determine the trophic support profile of the sensory neurons generated in vitro as one criterion to identify their subtype. Proprioceptive or mechanoreceptive sensory neurons require NT-3 or BDNF, while nociceptive sensory neurons require NGF or LIF (for review see Snider, 1994).

Explants were grown for 8 days in DM or DM supplemented on day 3 with NGF, LIF, NT3 or BDNF alone or in combination. Explants grown in DM contain hundreds of sensory neurons at day 4 (Fig. 3A,B and data not shown), but very few Brn-3.0 $0^{+}$cells survived after 8 days of culture (Fig. 9, 'No Add'), suggesting that these neurons die in the absence of exogenous trophic support. Addition of $100 \mathrm{ng} / \mathrm{ml}$ of NGF or $50 \mathrm{ng} / \mathrm{ml}$ of LIF at day 3 did not effect a significant increase in the number of surviving Brn-3.0 $0^{+}$cells (Fig. 9, NGF and LIF). Medium supplemented with $50 \mathrm{ng} / \mathrm{ml}$ of NT3 or BDNF, however, supported the survival of significantly more sensory neurons than were obtained in NGF or LIF (Fig. 9, NT3 and BDNF). When explants were grown in both BDNF and NT3, more sensory neurons survived than with either factor alone (Fig. 9, +NT3 +BDNF). Similar numbers of Brn-3.0 $0^{+}$cells were observed in cultures grown in NT3 plus BDNF compared to those cultured in the entire cocktail of factors (Fig. 9, +NGF $+\mathrm{LIF}+\mathrm{NT} 3+\mathrm{BDNF}$ ). Therefore, our cultures contain sensory
Fig. 7. Early sensory precursor-specific transcription factors are expressed in neural tube explant cultures at day 1 . (A-F) Cells in the neural crest outgrowth (below dashed line) of explants grown in defined medium for 1 day express in situ signal (blue) for $n g n 2$ (B,E, arrows), and neuroD (C,F, arrows), and are immunopositive for Brn-3.0 (D, blue nuclei; E,F, brown nuclei, arrowheads). (A) At this stage ngnl expression is restricted to the neural tube (cells above dashed line).

(E) Most $n g n 2^{+}$cells (arrows) do not co-express Brn-3.0 (arrowheads), although a few double-labeled cells can be found (inset). (F) In contrast, most neuro $D^{+}$cells (arrows) do express Brn-3.0 (arrowheads; inset) The extent of the outgrowth is visualized with DAPI fluorescence (aqua).

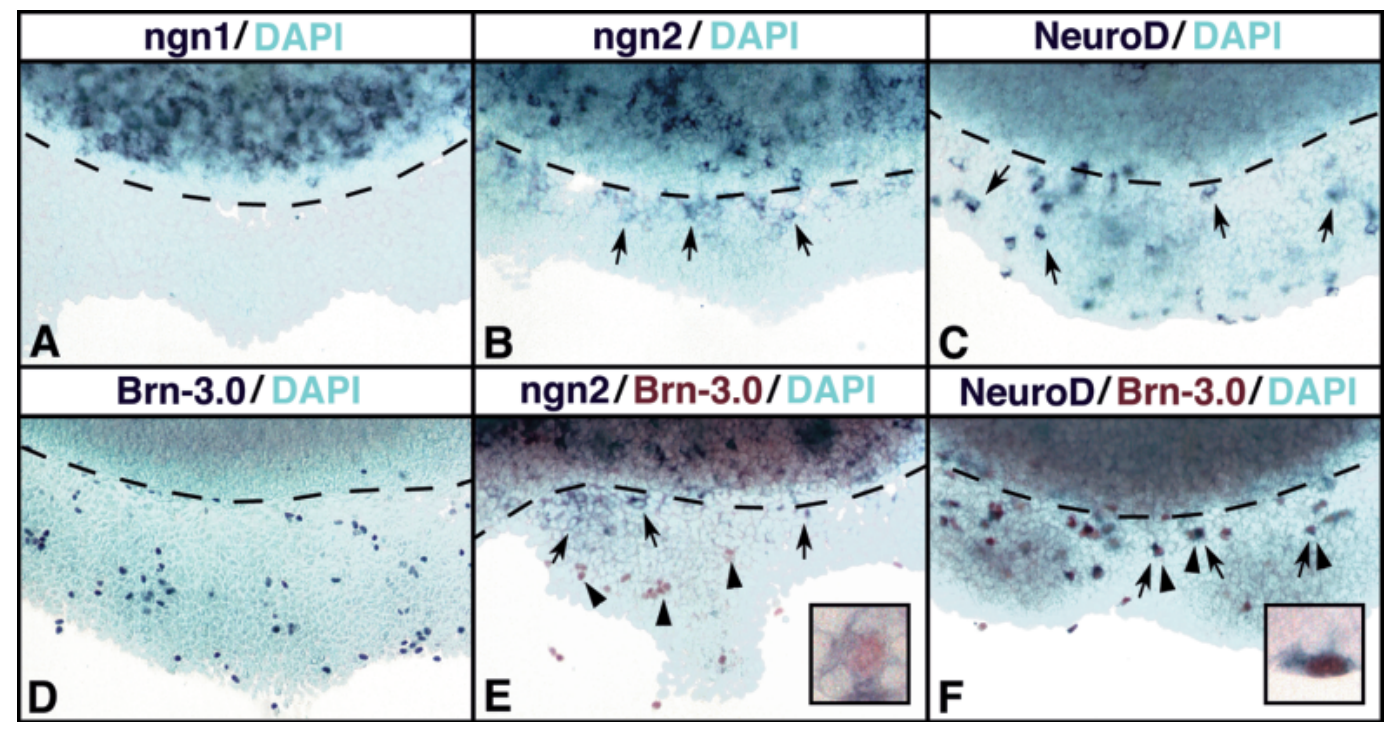


neurons that can be supported by NT3 and BDNF, but not by NGF or LIF.

Different subpopulations of sensory neurons are also known to have distinct profiles of gene expression (e.g., see Lawson, 1992 for review). We therefore characterized the sensory neurons that appeared in explants grown for 8 days in DM supplemented with all four neurotrophic factors to determine if they expressed markers known to correlate with a particular class of sensory neurons. We found that sensory neurons grown under these conditions expressed a highly phosphorylated form of neurofilament recognized by the monoclonal antibody RT97 (Fig. 10A), the expression of which in vivo correlates with the large proprioceptive subpopulation of sensory neurons (Lawson et al., 1984). Additionally, the large neurons in neural

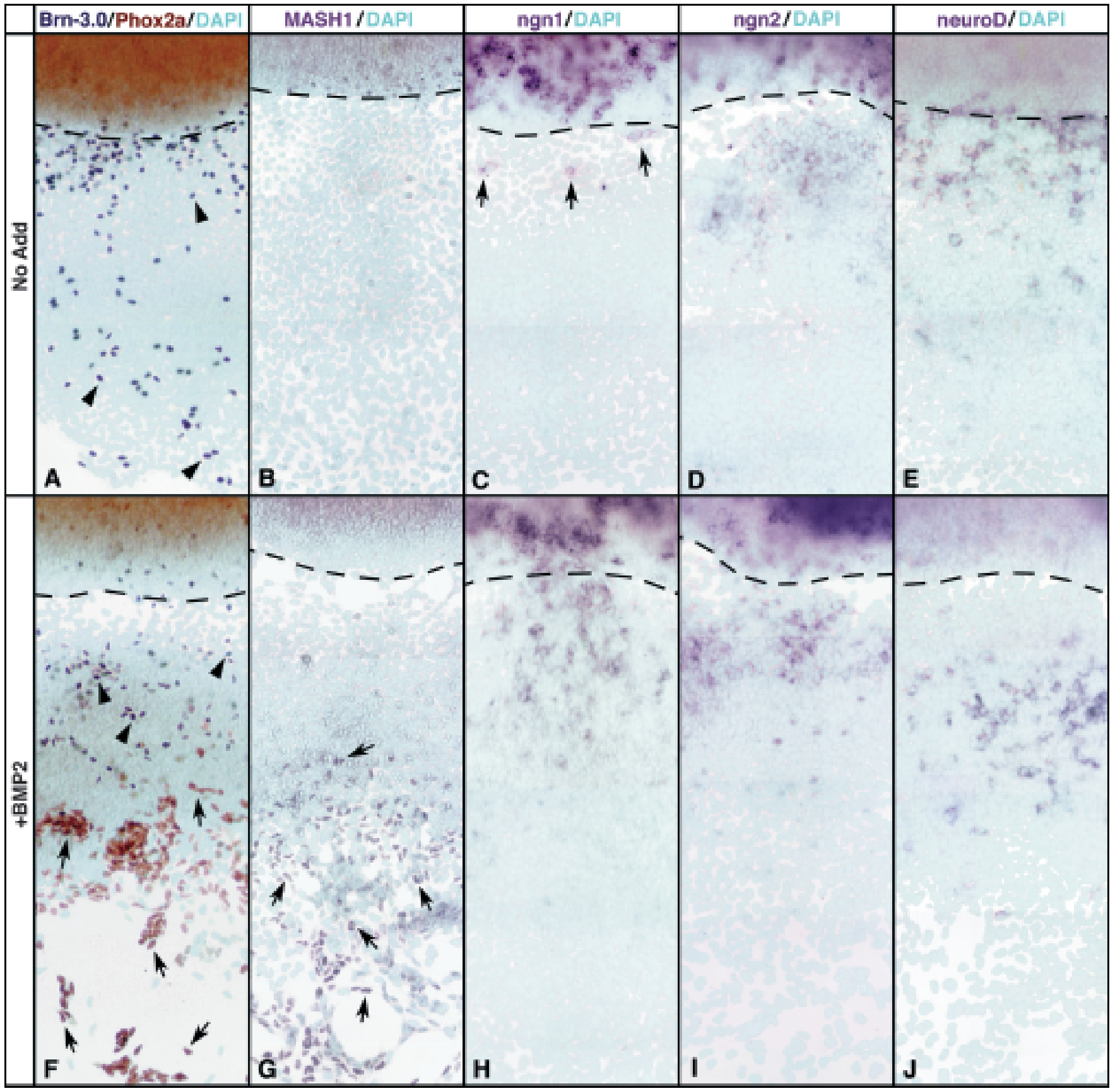

Fig. 8. Sensory precursor-specific markers persist in the presence of BMP2. Neural tube explants were grown in DM for 2 days in the absence (A-E) or presence (F-J) of BMP2. (A,F) Double labeling for Brn-3.0 (dark blue, arrowheads) and Phox2a (brown, arrows) shows that Brn-3.0 $0^{+}$ cells (arrowheads) are found in both conditions (A,F, arrowheads), but Phox $2 \mathrm{a}^{+}$cells (arrows) are found only in the presence of BMP2 (F). $(B, G)$ Similarly, cells immunopositive for MASH1 (arrows, purple nuclei) are found only in BMP2-treated explants (G) but not in 'No Add' conditions (B). (C-E versus H-J, purple in situ signal) At this stage, explants grown in the absence of BMP2 (C-E) contain a few cells in the outgrowth expressing $n g n 1$ (C, arrows), and many more expressing ngn2 (D) and neuroD (E). Explants grown in the presence of BMP2 (H-J), contain cells expressing similar or greater levels of $n g n 1(\mathrm{H}), n g n 2(\mathrm{I})$, and neuroD (J). 


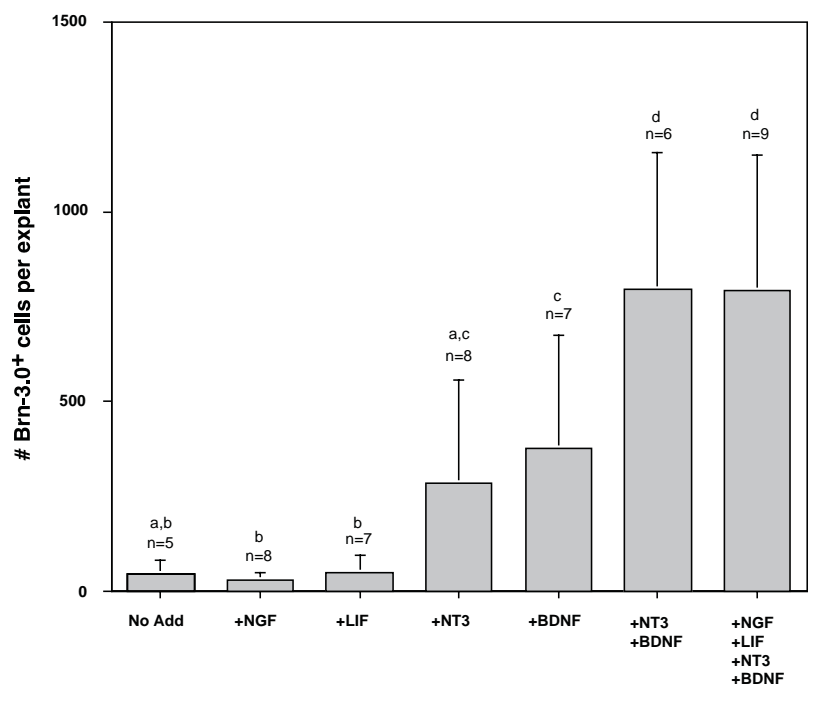

Fig. 9. NT3 and BDNF, not NGF or LIF, support significant populations of explant-derived sensory neurons. The graph represents the total number of Brn-3.0 $0^{+}$cells in the neural crest outgrowth per explant cultured for 8 days in defined medium in the absence or presence of different neurotrophins. There are more Brn$3.0^{+}$cells in cultures grown in NT3 or BDNF than in cultures grown in DM ('No Add'), NGF or LIF. Cultures grown in NT3+BDNF and $\mathrm{NGF}+\mathrm{LIF}+\mathrm{NT} 3+\mathrm{BDNF}$ contain significantly more Brn-3.0 $0^{+}$cells than other conditions. $\mathrm{n}$ is the number of explants counted from 2-4 experiments. Error is represented as standard deviation. Statistics were compared by ANOVA followed by pair-wise $t$-tests.

Statistically significant differences $(P<0.05)$ are indicated by letters (e.g., $a$ is different from $b$, but not from $a$ or $a, b)$.

crest explants expressed ER81 (Fig. 10B), an ETS domain transcription factor also restricted to the proprioceptive sensory subtype (Lin et al., 1998). Conversely, these neurons did not show detectable expression of markers that correlate with the nociceptive phenotype (for reviews see Hunt et al., 1992; Akopian et al., 1996): the neuropeptides, SP (Fig. 10C) and CGRP (Fig. 10D), or trkA, the high-affinity receptor for NGF (data not shown).

\section{DISCUSSION}

The timing and mechanism of sensory and autonomic lineage segregation have been of interest for many years (Le Lievre et al., 1980; Schweizer et al., 1983; Le Douarin, 1986; Le Douarin et al., 1994). Here we have established a culture system in which mammalian sensory neurons differentiate from proliferating precursors in a defined medium. Although BMP2 induces massive autonomic neurogenesis in such explants, it does not prevent sensory neurogenesis. Furthermore, the survival and/or proliferation of early sensory precursors, identified by expression of several sensory-specific transcription factors, is not abolished by BMP2. These data provide evidence that a subset of neural crest cells are, operationally, committed to a sensory fate with respect to an autonomic inducing cue that is likely to be relevant in vivo (Reissman et al., 1996; Shah et al., 1996). Strikingly, the sensory neurons that develop from these precursors appear to assume a proprioceptive and/or mechanoreceptive, rather than

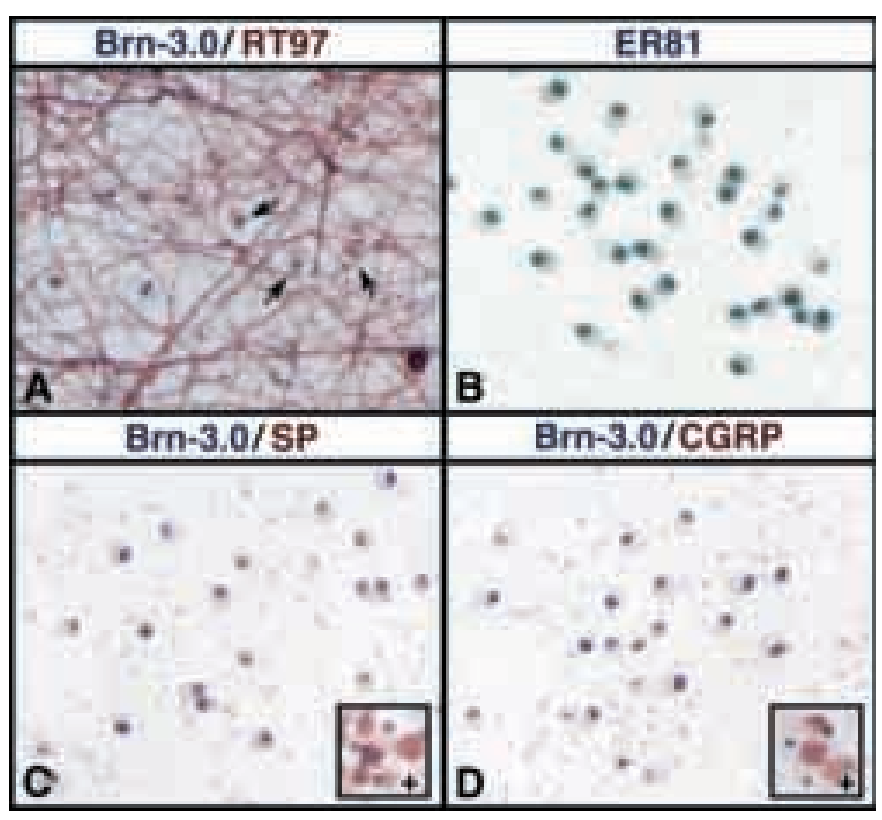

Fig. 10. Explant-derived sensory neurons express proprioceptive but not nociceptive, sensory subtype markers. (A-D) Neural tube explants were grown in defined medium in the presence of NGF, LIF, NT3 and BDNF for 8 days and stained for sensory subtype markers. (A) Double immunostaining for Brn-3.0 (dark blue nuclear) and RT97 (brown, cytoplasmic) reveals cells that co-express both markers (arrows) as well as many $\mathrm{RT} 7^{+}$processes. (B) The large diameter cells in these explants also express ER81 (dark blue, nuclear), a marker of proprioceptive sensory neurons (Lin et al., 1998). (C,D) In contrast, Brn-3.0+ cells in these cultures (dark blue, nuclear) do not express detectable levels of SP (C) or CGRP (D) staining (brown, cytoplasmic), compared to dissociated postnatal DRGs stained in parallel as a positive control (C,D insets).

nociceptive, phenotype. Such precursors may therefore correspond to a lineally (Frank and Sanes, 1991) and genetically (Ma et al., 1999) distinct subset of earlydifferentiating sensory precursors recently identified in vivo.

\section{Mammalian sensory neurogenesis in vitro}

Considerable ambiguity has surrounded the identification of sensory neurons in mammalian neural crest cultures due to a lack of definitive markers. For example, large numbers of 'sensory-like' neurons, identified by expression of calcitonin gene-related peptide (CGRP) and SubstanceP (SP) were shown to differentiate in mouse neural tube explant cultures (Murphy et al., 1991, 1994). These authors acknowledged that CGRP and SP are not definitive sensory markers; for example, they can be expressed by sympathetic neurons under certain conditions (Nawa and Patterson, 1990; Fann and Patterson, 1994a,b). Indeed, other studies have shown that CGRP and SP can be co-expressed with autonomic markers in individual neurons that develop from mouse neural crest cells when they are grown in an undefined medium (Matsumoto, 1994a,b). In our hands, neural crest cultures grown for long periods (8 days) in an undefined medium contain, qualitatively, many more autonomic than sensory neurons. Therefore, it is possible that many, if not all, of the 'sensory-like' neurons observed in cultures of mouse neural crest grown in undefined conditions 
(Murphy et al., 1991, 1994) may in fact have been autonomic in nature. Alternatively, these neurons may have been of the nociceptive sensory subtype, which express CGRP and SP in vivo and which do not develop under the culture conditions described here.

In both mammalian and avian systems, early-differentiating sensory-like neurons in neural crest cultures have been reported to arise from postmitotic precursors (Ziller et al., 1987; Sieber-Blum, 1989; Matsumoto, 1994b). Using BrdU labeling, we have demonstrated that virtually all the Brn-3.0 $0^{+}$ sensory precursors present in our cultures at day 1 are proliferating and that they continue to divide for the next 1-2 days. Consistent with this, cell division also persists after the initial expression of Brn-3.0 by sensory precursors in vivo (Fedtsova and Turner, 1995). A likely explanation for the difference between our results and those obtained in mouse neural crest cultures (Matsumoto, 1994b) is that the concentration of BrdU used in the earlier study $(10 \mu \mathrm{M})$ was toxic to sensory precursors. In this study, we used $175 \mathrm{nM}$ BrdU to label sensory precursors; we found that $10 \mu \mathrm{M}$ BrdU disrupted explant morphology and abolished Brn-3.0 expression, although BrdU was incorporated into many cells (A. G. and D. J. A., unpublished data). The establishment of a system in which mammalian sensory neurons differentiate de novo from proliferating precursors in a defined medium now opens the way to more detailed studies of the cellintrinsic and cell-extrinsic factors controlling their development.

Fig. 11. Origins of sensory neurons in vitro and in vivo. $(A, B)$ Alternative explanations for our in vitro observations; (C) represents a speculative model for sensory neurogenesis in vivo. In this schematic, straight arrows indicate potential and curved arrows indicate division, not self-renewal. (A) Sensory precursors $\left(\mathrm{P}_{\mathrm{S}}\right)$ and their progeny do not have the potential to execute an autonomic neuronal fate $\left(\mathrm{N}_{\mathrm{A}}\right)$ in response to BMP2. Instead, they generate only sensory neurons $\left(\mathrm{N}_{\mathrm{S}}\right)$ or sensory neurons and glia (G). In this model, autonomic neurons are derived from a separate population of precursors $\left(\mathrm{P}_{\mathrm{AGM}}\right)$, which are assumed to have glial and myofibroblast (M) potential like neural crest stem cells (Shah et al., 1996; Morrison et al., 1999). (B) A common precursor to sensory and autonomic neurons (PSAGM) whose sensory differentiation is not inhibited by BMP2. Such a model assumes that this cell undergoes obligate asymmetric divisions that generate a sensory precursor $\left(\mathrm{P}_{\mathrm{S}}\right)$ and a BMP2-responsive autonomic progenitor ( $\left.\mathrm{P}_{\mathrm{AGM}}\right)$. The sensory daughter of the asymmetric division may divide symmetrically before it differentiates (not illustrated). (C) Two classes of sensory progenitors are postulated to exist in vivo: those committed to a sensory fate $\left(\mathrm{P}_{\mathrm{S} 1}\right)$ and those that can generate both autonomic and sensory neurons ( $\left.\mathrm{P}_{\mathrm{S} 2 / \mathrm{A}}\right)$. The former are $n$ gn-2-dependent (Ma et al., 1999) and are fated to generate primarily largediameter (proprioceptive/mechanoreceptive) sensory neurons (Frank and Sanes, 1991), but are not necessarily committed to this sensory subtype. The latter give rise to both autonomic progenitors ( $\mathrm{P}_{\mathrm{AGM}}$ ) and $n g n l$-dependent sensory precursors $\left(\mathrm{P}_{\mathrm{S} 2}\right)$. These sensory precursors generate both large-diameter and small-diameter (nociceptive) sensory neurons (Frank and Sanes, 1991; Ma et al., 1999).

\section{The neural crest contains dividing precursors that generate sensory neurons even in the presence of an autonomic-inducing signal}

Our results point to the existence of a subpopulation of dividing neural crest cells that execute a sensory neuron fate whether or not they are challenged with BMP2, an autonomic-inducing cue. In this sense, these precursors appear 'committed' to a sensory neuron fate. Under these defined culture conditions, autonomic neurons do not differentiate unless BMP2 is added to the medium. The simplest explanation for these observations is that there are separate precursors for sensory and autonomic neurons in our cultures (Fig. 11A, $\mathrm{P}_{\mathrm{S}}$ and $\mathrm{P}_{\mathrm{AGM}}$, respectively). However, it is also formally possible that the cultures contain multipotent progenitors that generate both sensory and autonomic neurons in BMP2 (Fig. 11B, PSAGM). In order to explain why BMP2 would not induce autonomic neurogenesis from such progenitors at the expense of a sensory fate, it is necessary to make two independent assumptions: first, these multipotent cells must be themselves unresponsive to BMP2 (Fig. 11B, PSAGM), but divide to generate an autonomic

\section{A. SEPARATE SENSORY AND AUTONOMIC} PRECURSORS
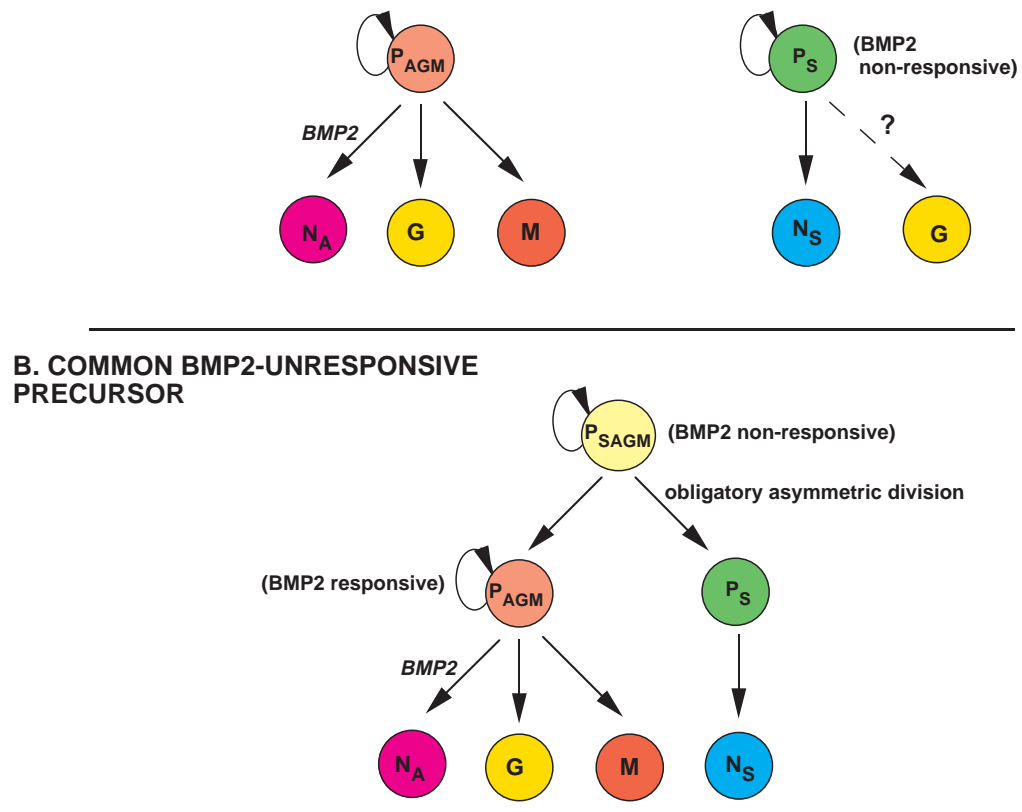

\section{TWO KINDS OF SENSORY PROGENITORS}

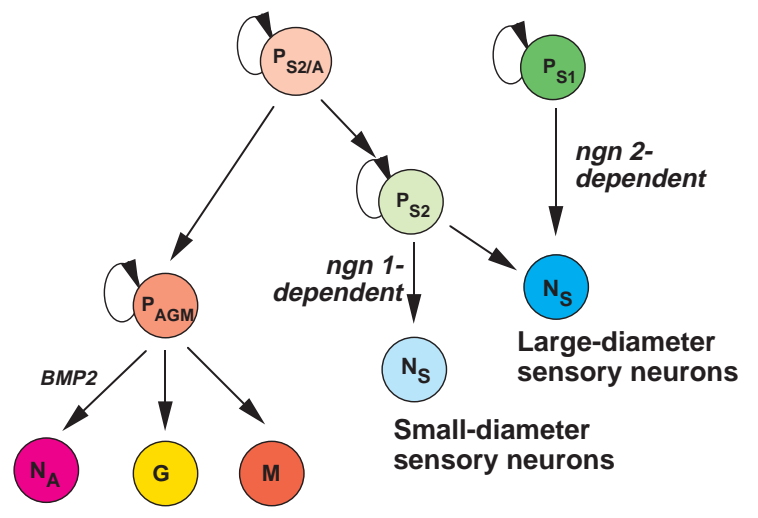


progenitor that is BMP2-responsive (Fig. 11B, $\mathrm{P}_{\mathrm{AGM}}$ ); second, such cell divisions must be asymmetric, so as to always generate a daughter that differentiates into a sensory neuron even in the presence of BMP2 (Fig. 11B, PS). (Alternatively, equivalent cells could divide symmetrically to generate with equal probability either sensory or autonomic precursors.) In this way, such precursors would be 'committed' to generating sensory neurons in BMP2, but not be restricted from an autonomic fate. The inability to obtain sensory neuron differentiation in clonal cultures (A. G. and D. J. A., unpublished observations) and the low percentage of sensory neurons that develop in our explants makes it difficult to distinguish between these models by direct lineage analysis. However, we favor the former model (Fig. 11A) because it makes fewer assumptions.

Our use of BMP2 to challenge sensory precursors raises the question of whether this factor is a biologically relevant signal for testing the commitment state of these cells. BMPfamily members have been shown to induce autonomic differentiation in a highly robust manner in multiple contexts. BMP2, BMP4 and BMP7 are able to induce expression of autonomic markers in cultures of neural crest cells from either avian (Varley et al., 1995; Reissman et al., 1996; Varley and Maxwell, 1996) or mammalian (Shah et al., 1996; Shah and Anderson, 1997; Morrison et al., 1999) embryos. Overexpression of BMPs in vivo has also been shown to induce autonomic markers (Reissman et al., 1996). In vivo, BMPs are expressed by tissues (e.g., dorsal aorta) near sites of autonomic differentiation (Reissman et al., 1996; Shah et al., 1996) and these tissues can mimic the inductive effects of BMPs (Reissman et al., 1996). Taken together, these data argue that BMP family members are likely acting as autonomic inducers in vivo. Therefore, although the sensory precursors that we have studied may not be committed with respect to other inductive cues, their insensitivity to BMP2 is likely to be of particular significance for sensory development in vivo.

BMP2 also constitutes a particularly stringent challenge of sensory precursors because it has been shown to act instructively on rat neural crest stem cells, causing them to adopt an autonomic neuronal fate at the expense of alternative fates (Shah et al., 1996). Because our assay for sensory neurogenesis could not be performed using clonal cultures, we were unable directly demonstrate that BMP2 acts instructively in this system. However, the large induction of autonomic markers that occurs during a 24 hour exposure to this factor (approximately, 0\% Phox $2 \mathrm{a}^{+}$cells in 'No Add' versus $25-50 \%$ in BMP2; see also Fig. 6) is consistent with an instructive effect of BMP2. Given that BMP2 has been shown to act instructively on rat neural crest cells isolated from two different sources and grown in two different culture media (Shah et al., 1996; Morrison et al., 1999), it is highly likely that the factor acts instructively in this system as well.

Earlier studies in avian embryos have been interpreted to suggest that the neural crest contains a subset of precursors restricted to a sensory fate (Ziller et al., 1987; Sieber-Blum, 1989; Duff et al., 1991). Although this general conclusion is similar to that which we have drawn here, the evidence supporting it differs in several important respects from our own results. In one series of experiments, sensory-like neurons were observed to differentiate in a defined medium; sensory differentiation was prevented by serum, which promoted autonomic neurogenesis (Ziller et al., 1983, 1987). These observations were interpreted to suggest that sensory neurons developed from separate precursors that were restricted from an autonomic fate. However, since sensory neurons failed to appear in serum-containing medium, it could not be determined whether the sensory precursors died or were converted to other fates. Other investigators have also concluded that some sensory precursors are restricted from an autonomic fate because they do not produce autonomic neurons under culture conditions that allow autonomic neurogenesis (Sieber-Blum, 1989; Duff et al., 1991). In neither of these studies, however, were the sensory precursors challenged by addition of defined, instructive autonomicinducing signals. The fact that autonomic neurons differentiate under a given set of culture conditions may simply reflect the presence of factors permissive for such differentiation, in which case they are not an adequate challenge of the state of commitment of sensory precursors.

\section{Multiple sensory sublineages in the neural crest}

The ability of some neural crest cells to give rise to both sensory and autonomic neurons in vivo is well-documented (Bronner-Fraser and Fraser, 1988, 1989; Fraser and BronnerFraser, 1991). Nevertheless, the notion that migrating neural crest also contains a subpopulation of precursors determined for a sensory fate is still consistent with the results of such lineage analyses. In one study, almost 50\% (8/17) of migrating avian neural crest cells injected with a lineage tracer produced neurons exclusively in the DRG, rather than in both the DRG and sympathetic ganglia (Fraser and Bronner-Fraser, 1991). From such a lineage analysis alone, it is not possible to distinguish whether these clonal differences represent stochastic variations in fate among a developmentally equivalent precursor population, or rather distinct subpopulations that are intrinsically different. The present observations are consistent with the possibility that some lineage-marked crest cells that generated only sensory neurons in vivo were in fact determined for a sensory fate. Interestingly, a recent clonal analysis of migrating crest in vitro suggests that many precursors are fated to generate only neuronal progeny, although whether these neurons were sensory or autonomic was not investigated (Henion and Weston, 1997).

Our observations, taken together with previous studies, support the notion that there may be at least two classes of sensory precursors in the neural crest: those that are determined for a sensory fate early in neural crest ontogeny, and those that have a wider range of potentials including both sensory and autonomic fates (Bronner-Fraser and Fraser, 1988, 1989; Sieber-Blum, 1989; Fraser and Bronner-Fraser, 1991). Interestingly, sensory precursors in our cultures generate neurons that are predominantly of the proprioceptive or mechanoreceptive subtypes. Such cells may therefore correspond to a distinct sublineage of early-differentiating precursors that generate large-diameter sensory neurons (Fig. $\left.11 \mathrm{C}, \mathrm{P}_{\mathrm{S} 1}\right)$ that have been identified by a previous in vivo retroviral clonal analysis in chick (Frank and Sanes, 1991). Similar precursors are genetically dependent on ngn2 but not ngnl in mice (Ma et al., 1999). This correspondence does not mean that ngn2-dependent precursors are necessarily committed to a proprioceptive/ mechanoreceptive subtype; for 
example, they may simply differentiate at a time when signals that promote these subtypes are present.

If the progenitors that appear committed to a sensory fate in our cultures correspond to those fated to generate earlydifferentiating proprioceptive and mechanoreceptive neurons in vivo, then perhaps the common progenitors of sensory and autonomic neurons (Fig. 11C, $\mathrm{P}_{\mathrm{S} 2 / \mathrm{A}}$ ) identified by in vivo lineage tracing (Bronner-Fraser and Fraser, 1988, 1989; Fraser and Bronner-Fraser, 1991) are cells that give rise to the laterdifferentiating subpopulation of sensory precursors (Fig. 11C, $\mathrm{P}_{\mathrm{S} 2}$; Lawson et al., 1974; Carr and Simpson, 1978; Lawson and Biscoe, 1979; Frank and Sanes, 1991). Such latedifferentiating sensory precursors have been shown to be $n g n 1$ dependent (Ma et al., 1999), and to give rise to both smalldiameter (nociceptive) and large-diameter (proprioceptive/ mechanoreceptive) neurons (Frank and Sanes, 1991; E. Frank, personal communication). At present it is not clear why only the early-differentiating sensory precursors develop in our cultures. One possibility is that the later-differentiating precursors may not migrate from the explanted neural tube. Alternately, they may migrate but not differentiate into, or survive as, nociceptive sensory neurons. In the absence of conditions to elicit differentiation of such nociceptive neurons, we cannot say whether the BMP2-responsive autonomic precursors do or do not have sensory potential. These cells may correspond to a common sensory-autonomic precursor from which we are currently able to elicit autonomic but not sensory neurogenesis (Fig. 11C, $\mathrm{P}_{\mathrm{S} 2 / \mathrm{A}}$ ); alternately, they may already be restricted to an autonomic fate (Fig. 11C, PAGM).

\section{Early determination of some sensory precursors may prevent them from responding to autonomic- inducing signals as they migrate}

When do sensory precursors become determined? Our data reveal a correlation between the resistance of sensory precursors to an autonomic inducing signal and the persistence of $n g n 2$-expressing cells despite the presence of this signal. Forced expression of ngns in chick neural crest cells in ovo can bias their distribution to the DRG and can induce sensory-specific genes including Brn-3.0 (Perez et al., 1999; S. Perez and D. J. A., unpublished data). These data are consistent with the idea that some progenitors may become determined for a sensory fate as early as the time they express $n g n 2$. In vivo, $n g n 2$ is expressed by a subset of neural crest cells early in migration (Gradwohl et al., 1996; Sommer et al., 1996; Perez et al., 1999; Ma et al., 1999). Therefore, early expression of $n g n 2$ may identify a subset of neural crest cells that are specified for a sensory fate shortly after they emigrate from the neural tube, a conclusion consistent with some results from the in vivo lineage-tracing experiments mentioned earlier (Fraser and Bronner-Fraser, 1991). These cells may be similar or equivalent to those that we have studied here in vitro.

The early determination of some sensory precursors among the migrating neural crest may serve to make them resistant to the autonomic-inducing effects of locally expressed BMPfamily members. Although these factors are likely to be important for autonomic neurogenesis in vivo, these same BMPs are also expressed in many tissues in the dorsal part of the embryo where autonomic neurons do not develop, including dorsal ectoderm (Liem et al., 1995), the dorsal neural tube (Liem et al., 1997) and the developing somites (Reshef et al., 1998). Because migrating neural crest cells are likely to encounter BMP family members in the dorsal part of the embryo, mechanisms must exist that prevent them from differentiating into autonomic neurons in this location. The early determination of some sensory progenitors with respect to BMPs may represent one such strategy. The fact that such determination occurs while the precursors are still mitotically active, moreover, would allow for the continued expansion of the sensory neuron population by postmigratory cells during the growth of the DRG (Duff et al., 1991). In this way, the early determination of a subset of dividing neural crest cells may play an important role in the growth and development of sensory ganglia.

We thank Li Ching Lo, Andy Groves, Sean Morrison, Nirao Shah and Lukas Sommer for helpful suggestions and advice pertaining to tissue culture and medium formulation. We thank $\mathrm{H}$. Phan and L. Wang for technical help and G. Mosconi for laboratory management. Thanks also to S. Arber, J. F. Brunet, C. Goridis, T. Jessell, L. Reichardt and J. N. Wood for supplying essential antibody reagents, to G. Yancopoulos/Regeneron for NT-3 and BDNF, and to V. Rossen/Genetics Institute for BMP2. We thank S. Perez, A. Paquette, S. Gerety, P. Patterson, R. Lahav, S. Fraser and M. Bronner-Fraser for critical reading of the manuscript. This work was supported by a grant from the March of Dimes Foundation. D. J. A. is an Investigator of the Howard Hughes Medical Institute.

\section{REFERENCES}

Akopian, A. N., Abson, N. C. and Wood, J. N. (1996). Molecular genetic approaches to nociceptor development and function. Trends Neurosci. 19, 240-246.

Anderson, D. J. (1989). The neural crest cell lineage problem: Neuropoiesis? Neuron 3, 1-12.

Anderson, D. J. (1993). Cell and molecular biology of neural crest cell lineage diversification. Curr. Opin. Neurobiol. 3, 8-13.

Anderson, D. J. (1997). Cellular and molecular biology of neural crest cell lineage determination. Trends Genet. 13, 276-280.

Bronner-Fraser, M. and Fraser, S. (1988). Cell lineage analysis shows multipotentiality of some avian neural crest cells. Nature 335, 161-164.

Bronner-Fraser, M. and Fraser, S. (1989). Developmental potential of avian trunk neural crest cells in situ. Neuron 3, 755-766.

Bronner-Fraser, M. E. (1993). Segregation of cell lineage in the neural crest. Curr. Opin. Gen. Devel. 3, 641-647.

Carr, V. M. and Simpson, S. B. (1978). Proliferative and degenerative events in the early development of chick dorsal root ganglia. J. Comp. Neurol. 182, 727-740.

Clary, D. O., Weskamp, G., Austin, L. R. and Reichardt, L. F. (1994). TrkA cross-linking mimics neuronal responses to nerve growth factor. Mol. Biol. Cell 5, 549-563.

Duff, R. S., Langtimm, C. J., Richardson, M. K. and Sieber-Blum, M. (1991). In vitro clonal analysis of progenitor cell patterns in dorsal root and sympathetic ganglia of the quail embryo. Dev. Biol. 147, 451-459.

Fann, M.-J. and Patterson, P. H. (1994a). Depolarization differentially regulates the effects of bone morphogenetic protein (BMP)-2, BMP-6, and Activin-A on sympathetic neuronal phenotype. J. Neurochem. 63, 2074 2079.

Fann, M.-J. and Patterson, P. H. (1994b). Neuropoietic cytokines and activin A differentially regulate the phenotype of cultured sympathetic neurons Proc. Natl. Acad. Sci. USA 91, 43-47.

Fedtsova, N. G. and Turner, E. E. (1995). Brn-3.0 expression identified early post-mitotic CNS neurons and sensory neural precursors. Mech. Dev. 53, 291-304.

Fode, C., Gradwohl, G., Morin, X., Dierich, A., LeMeur, M., Goridis, C. and Guillemot, F. (1998). The bHLH protein NEUROGENIN 2 is a determination factor for epibranchial placode-derived sensory neurons. Neuron 20, 483-494. 
Frank, E. and Sanes, J. R. (1991). Lineage of neurons and glia in chick dorsal root ganglia: analysis in vivo with a recombinant retrovirus. Development 111, 895-908.

Fraser, S. E. and Bronner-Fraser, M. E. (1991). Migrating neural crest cells in the trunk of the avian embryo are multipotent. Development 112, 913920.

Gradwohl, G., Fode, C. and Guillemot, F. (1996). Restricted expression of a novel murine atonal-related bHLH protein in undifferentiated neural precursors. Dev. Biol. 180, 227-241.

Groves, A. K. and Anderson, D. J. (1996). Role of environmental signals and transcriptional regulators in neural crest development. Dev. Genet. 18, 6472.

Hawrot, E. and Patterson, P. H. (1979). Long-term culture of dissociated sympathetic neurons. Methods in Enzymology 58, 574-583.

Henion, P. D. and Weston, J. A. (1997). Timing and pattern of cell fate restrictions in the neural crest lineage. Development 124, 4351-4359.

Henrique, D., Adam, J., Myat, A., Chitnis, A., Lewis, J. and Ish-Horowicz, D. (1995). Expression of a Delta homologue in prospective neurons in the chick. Nature 375, 787-790.

Hunt, S. P., Mantyh, P. W. and Priestly, J. V. (1992). The organization of biochemically characterized sensory neurons. In Sensory Neurons: Diversity, Development, and Plasticity. (ed. S. A. Scott). pp. 60-76. New York: Oxford University Press.

Johnson, J. E., Birren, S. J. and Anderson, D. J. (1990). Two rat homologues of Drosophila achaete-scute specifically expressed in neuronal precursors. Nature 346, 858-861.

Lawson, S. N. (1992). Morphological and Biochemical Cell Types of Sensory Neurons. In Sensory Neurons: Diversity, Development, and Plasticity. (ed. S. A. Scott). pp. 27-59. New York: Oxford University Press.

Lawson, S. N. and Biscoe, T. J. (1979). Development of mouse dorsal root ganglia: an autoradiographic and quantitative study. J. Neurocytol. 8, 265274.

Lawson, S. N., Caddy, K. W. T. and Biscoe, T. J. (1974). Development of rat dorsal root ganglion neurones: studies of cell birthdays and changes in mean cell diameters. Cell Tiss. Res. 153, 399-413.

Lawson, S. N., Harper, A. A., Harper, E. I., Garson, J. A. and Anderton, B. H. (1984). A monoclonal antibody against neurofilament protein specifically labels a subpopulation of rat sensory neurones. J. Comp. Neurol. 228, 263-272.

Le Douarin, N., Dulac, C., Dupin, E. and Cameron-Curry, P. (1991). Glial cell lineages in the neural crest. Glia 4, 175-184.

Le Douarin, N. M. (1986). Cell line segregation during peripheral nervous system ontogeny. Science 231, 1515-1522.

Le Douarin, N. M., Dupin, E. and Ziller, C. (1994). Genetic and epigenetic control in neural crest development. Curr. Opin. Gene. Dev. 4, 685-695.

Le Lievre, C. S., Schweizer, G. G., Ziller, C. M. and Le Douarin, N. M. (1980). Restrictions of developmental capabilities in neural crest cell derivatives tested by in vivo transplantation experiments. Dev. Biol. 77, 362378.

Lee, J. E., Hollenberg, S. M., Snider, L., Turner, D. L., Lipnick, N. and Weintraub, H. (1995). Conversion of Xenopus ectoderm into neurons by NeuroD, a basic helix-loop-helix protein. Science 268, 836-844.

Liem, K. F., Jr., Tremmel, G. and Jessell, T. M. (1997). A role for the roof plate and its resident TGF $\beta$-related proteins in neuronal patterning in the dorsal spinal cord. Cell 91, 127-138.

Liem, K. F., Tremml, G., Roelink, H. and Jessell, T. M. (1995). Dorsal differentiation of neural plate cells induced by BMP-mediated signals from epidermal ectoderm. Cell 82, 969-979.

Lin, J. H., Saito, T., Anderson, D. J., Lance-Jones, C., Jessell, T. M. and Arber, S. (1998). Functionally-related motor neuron pool and muscle sensory afferent subtypes defined by coordinate ETS gene expression. Cell 95, 393-407.

Lo, L., Tiveron, M.-C. and Anderson, D. J. (1998). MASH1 activates expression of the paired homeodomain transcription factor Phox2a, and couples pan-neuronal and subtype-specific components of autonomic neuronal identity. Development 125, 609-620.

Lo, L.-C. and Anderson, D. J. (1995). Postmigratory neural crest cells expressing c-ret display restricted developmental and proliferative capacities. Neuron 15, 527-539.

Lo, L.-C., Johnson, J. E., Wuenschell, C. W., Saito, T. and Anderson, D. J. (1991). Mammalian achaete-scute homolog 1 is transiently expressed by spatially-restricted subsets of early neuroepithelial and neural crest cells. Genes Dev. 5, 1524-1537.
Ma, Q., Fode, C., Guillemot, F. and Anderson, D. J. (1999) NEUROGENIN1 and NEUROGENIN2 control two distinct waves of neurogenesis in developing dorsal root ganglia. Genes Dev (in press).

Ma, Q., Chen, Z. F., Barrantes, I. B., de la Pompa, J. L. and Anderson, D. J. (1998). Neurogenin 1 is essential for the determination of neuronal precursors for proximal cranial sensory ganglia. Neuron 20, 469-482.

Ma, Q., Kintner, C. and Anderson, D. J. (1996). Identification of neurogenin, a vertebrate neuronal determination gene. Cell 87, 43-52.

Marusich, M. F. and Weston, J. A. (1991). Development of the neural crest. Curr. Opin. Genet. Dev. 1, 221-229.

Matsumoto, S. G. (1994a). Neuronal differentiation in cultures of murine neural crest. II. Development of capsaicin-sensitive neurons. Dev. Brain Res. 83, 17-27.

Matsumoto, S. G. (1994b). Neuronal differentiation in cultures of murine neural crest. I. Neurotransmitter expression. Dev. Brain. Res. 83, 1-16.

McEvilly, R. J., Erkman, L., Luo, L., Sawchenko, P. E., Ryan, A. F. and Rosenfeld, M. G. (1996). Requirement for Brn-3.0 in differentiation and survival of sensory and motor-neurons. Nature 384, 574-577.

Morrison, S. J., White, P. M., Zock, C. and Anderson, D. J. (1999). Prospective identification, isolation by flow cytometry, and in vivo selfrenewal of multipotent mammalian neural crest stem cells. Cell 96, 737-749.

Murphy, M., Reid, K., Ford, M., Furness, J. B. and Bartlett, P. F. (1994) FGF2 regulates proliferation of neural crest cells, with subsequent neuronal differentiation regulated by LIF or related factors. Development 120, 35193528.

Murphy, M., Reid, K., Hilton, D. J. and Bartlett, P. F. (1991). Generation of sensory neurons is stimulated by leukemia inhibitory factor. Proc. Natl. Acad. Sci. USA 88, 3498-3501.

Nawa, H. and Patterson, P. H. (1990). Separation and partial characterization of neuropeptide-inducing factors in heart cell conditioned medium. Neuron 4, 269-277.

Novitch, B. G., Mulligan, G. J., Jacks, T. and Lassar, A. B. (1996). Skeletal muscle cells lacking the retinoblastoma protein display defects in muscle gene expression and accumulate in S and G2 phases of the cell cycle. J. Cell Biol. 135, 441-456.

Pachnis, V., Mankoo, B. and Costantini, F. (1993). Expression of the c-ret proto-oncogene during mouse embryogenesis. Development 119, 10051017.

Parysek, L. M. and Goldman, R. D. (1988). Distribution of a novel $57 \mathrm{kDa}$ Intermediate Filament (IF) protein in the nervous system. J. Neurosci. 8 555-563.

Perez, S. E., Rebelo, S. and Anderson, D. J. (1999). Early specification of sensory neuron fate revealed by expression and function of neurogenins in the chick embryo. Development 126, 1715-1728.

Reissman, E., Ernsberger, U., Francis-West, P. H., Rueger, D., Brickell, P. D. and Rohrer, H. (1996). Involvement of bone morphogenetic protein-4 and bone morphogenetic protein-7 in the differentiation of the adrenergic phenotype in developing sympathetic neurons. Development 122, 20792088.

Reshef, R., Maroto, M. and Lassar, A. B. (1998). Regulation of dorsal somitic cell fates: BMPs and Noggin control the timing and pattern of myogenic regulator expression. Genes Dev. 12, 290-303.

Saito, T., Greenwood, A., Sun, Q. and Anderson, D. J. (1995). Identification by differential RT-PCR of a novel paired homeodomain protein specifically expressed in sensory neurons and a subset of their CNS targets. Mol. Cell. Neurosci. 6, 280-292.

Schweizer, Ayer-LeLievre and Douarin, L. (1983). Restrictions of developmental capacities in the dorsal root ganglia during the course of development. Cell Differentiation 13, 191-200.

Shah, N. M. and Anderson, D. J. (1997). Integration of multiple instructive cues by neural crest stem cells reveals cell-intrinsic biases in relative growth factor responsiveness. Proc. Natl. Acad. Sci. USA 94, 11369-11374.

Shah, N. M., Groves, A. and Anderson, D. J. (1996). Alternative neural crest cell fates are instructively promoted by TGF $\beta$ superfamily members. Cell $\mathbf{8 5}, 331-343$.

Shah, N. M., Marchionni, M. A., Isaacs, I., Stroobant, P. W. and Anderson, D. J. (1994). Glial growth factor restricts mammalian neural crest stem cells to a glial fate. Cell 77, 349-360.

Sieber-Blum, M. (1989). Commitment of neural crest cells to the sensory neuron lineage. Science 243, 1608-1610.

Sieber-Blum, M. (1990). Mechanisms of Neural Crest Diversification. In Comments Developmental Neurobiology, Vol. 1. pp. 225-249. Gordon and Breach Science Publishers, SA, Great Britain.

Sieber-Blum, M., Ito, K., Richardson, M. K., Langtimm, C. J. and Duff, 
R. S. (1993). Distribution of pluripotent neural crest cells in the embryo and the role of brain-derived neurotrophic factor in the commitment to the primary sensory neuron lineage. J. Neurobiol. 24, 173-184.

Snider, W. D. (1994). Functions of the neurotrophins during nervous system development - what the knockouts are teaching us. Cell 77, 627638.

Sommer, L., Ma, Q. and Anderson, D. J. (1996). neurogenins, a novel family of atonal-related bHLH transcription factors, are putative mammalian neuronal determination genes taht reveal progenitor cell heterogeneity in the developing CNS and PNS. Mol. Cell. Neurosci. 8, 221-241.

Stemple, D. L. and Anderson, D. J. (1992). Isolation of a stem cell for neurons and glia from the mammalian neural crest. Cell 71, 973-985.

Tiveron, M.-C., Hirsch, M.-R. and Brunet, J.-F. (1996). The expression pattern of the transcription factor Phox2a delineates synaptic pathways of the autonomic nervous system. J. Neurosci. 16, 7649-7660.

Valarché, I., Tissier-Seta, J.-P., Hirsch, M.-R., Martinez, S., Goridis, C. and Brunet, J.-F. (1993). The mouse homeodomain protein Phox2 regulates NCAM promoter activity in concert with Cux/CDP and is a putative determinant of neurotransmitter phenotype. Development 119, 881-896.

Varley, J. E. and Maxwell, G. D. (1996). BMP-2 and BMP-4, but not BMP6 , increase the number of adrenergic cells which develop in quail trunk neural crest cultures. Exp. Neurol. 140, 84-94.

Varley, J. E., Wehby, R. G., Rueger, D. C. and Maxwell, G. D. (1995). Number of adrenergic and islet-1 immunoreactive cells is increased in avian trunk neural crest cultures in the presence of human recombinant osteogenic protein-1. Dev. Dynam. 203, 434-447.

Weston, J. A. (1991). Sequential segregation and fate of developmentally restricted intermediate cell populations in the neural crest lineage. Curr. Topics Dev. Biol. 25, 133-153.

Xiang, M. Q., Gan, L., Zhou, L., Klein, W. H. and Nathans, J. (1996). Targeted deletion of the mouse POU domain gene Brn-3a causes a selective loss of neurons in the brain-stem and trigeminal ganglion, uncoordinated limb movement, and impaired suckling. Proc. Natl. Acad. Sci. USA 93, 11950-11955.

Xiang, M. Q., Zhou, L. J., Macke, J. P., Yoshioka, T., Hendry, S. H. C., Eddy, R. L., Shows, T. B. and Nathans, J. (1995). The Brn-3 family of POU-domain factors - primary structure, binding-specificity, and expression in subsets of retinal ganglion-cells and somatosensory neurons. J. Neurosci. 15, 4762-4785.

Ziller, C., Dupin, E., Brazeau, P., Paulin, D. and Le Douarin, N. M. (1983). Early segregation of a neural precursor cell line in the neural crest as revealed by culture in a chemically defined medium. Cell 32, 627-638.

Ziller, C., Fauquet, M., Kalcheim, C., Smith, J. and Le Douarin, N. M. (1987). Cell lineages in peripheral nervous system ontogeny: mediuminduced modulation of neuronal phenotypic expression in neural crest cultures. Dev. Biol. 120, 101-111.

Zimmerman, L. B., Dejesus-Escobar, J. M. and Harland, R. M. (1996) The Spemann organizer signal noggin binds and inactivates bone morphogenetic protein-4. Cell 86, 599-606. 